Melika Mohammadkhah, Dragan Marinković, Manfred Zehn, Sara Checa

\title{
A review on computer modeling of bone piezoelectricity and its application to bone adaptation and regeneration
}

Journal article | Accepted manuscript (Postprint)

This version is available at https://doi.org/10.14279/depositonce-10675

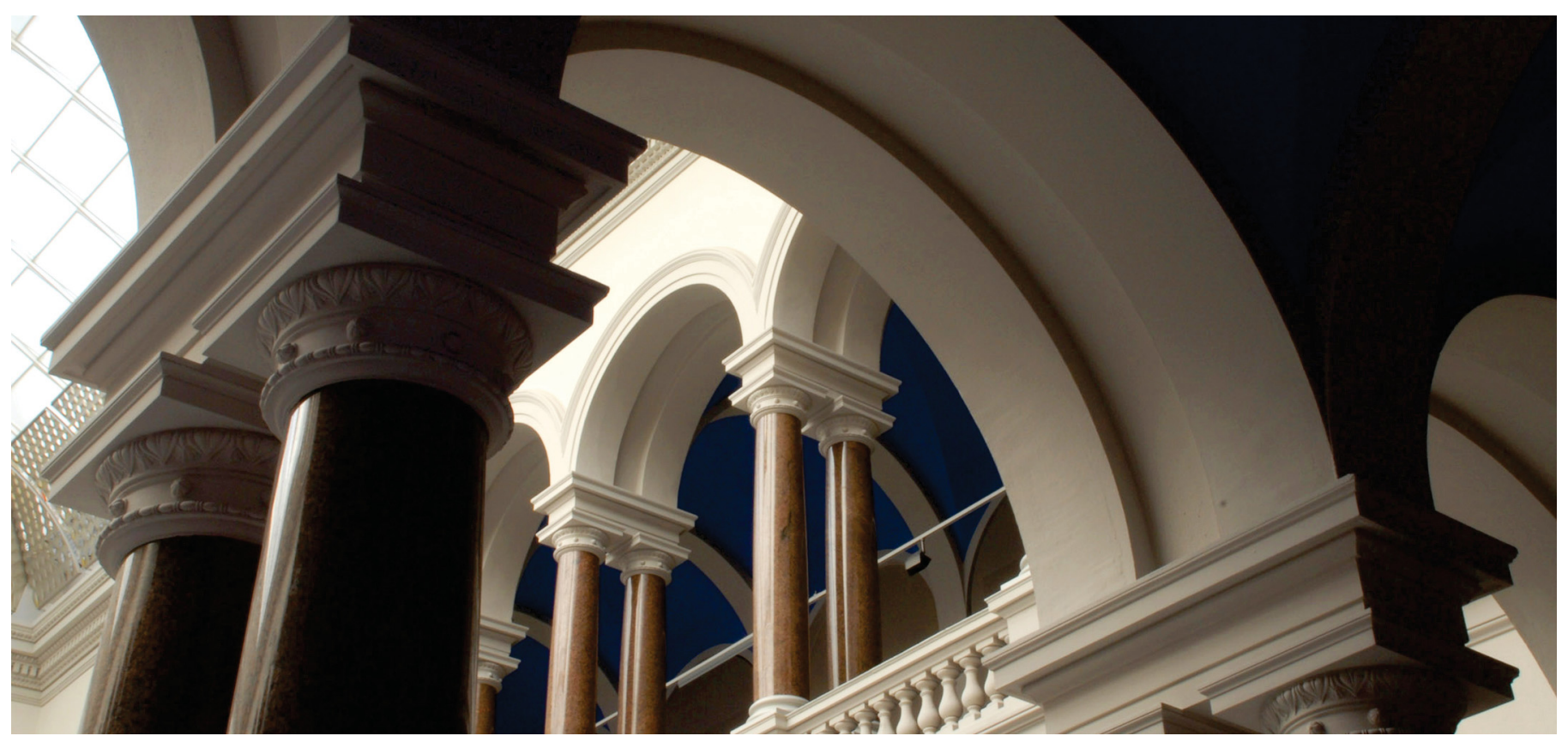

Mohammadkhah, M., Marinkovic, D., Zehn, M., \& Checa, S. (2019). A review on computer modeling of bone piezoelectricity and its application to bone adaptation and regeneration. Bone, 127, 544-555. https://doi.org/10.1016/j.bone.2019.07.024 


\title{
A review on computer modeling of bone piezoelectricity and its application to bone adaptation and regeneration
}

\author{
$\underline{\text { Melika Mohammadkhah }}{ }^{1}$, Dragan Marinkovic ${ }^{1,2}$, Manfred Zehn ${ }^{1}$, Sara Checa ${ }^{1,3}$ \\ ${ }^{1}$ Department of Structural Mechanics, Berlin Institute of Technology, Berlin, Germany \\ ${ }^{2}$ Faculty of Mechanical Engineering, University of Nis, Serbia \\ ${ }^{3}$ Julius Wolff Institute, Charité - Universitätsmedizin Berlin, Berlin, Germany
}

Melika Mohammadkhah ${ }^{1}$

melika.mohammadkhah@tu-berlin.de

Dragan Marinkovic ${ }^{1,2}$

dragan.marinkovic@tu-berlin.de

Manfred Zehn ${ }^{1}$

manfred.zehn@tu-berlin.de

Sara Checa ${ }^{1,3}$

sara.checa@charite.de

${ }^{1}$ Department of Structural Mechanics, Berlin Institute of Technology,

Fakultät V - Institut für Mechanik, FG Strukturmechanik und Strukturberechnung, Sekr. C 8-3, Geb. M Str. des 17. Juni 135, D-10623 Berlin, Germany

${ }^{2}$ Faculty of Mechanical Engineering, University of Nis, Serbia

Aleksandra Medvedeva 14, 18000 Nis, Serbia

${ }^{3}$ Julius Wolff Institute, Charité - Universitätsmedizin Berlin, Berlin, Germany

Julius Wolff Institute, Föhrer Str. 15, 13353 Berlin, Germany

\section{Corresponding author:}

Dr.-Ing. Melika Mohammadkhah

Technische Universität Berlin

Fakultät V - Institut für Mechanik

FG Strukturmechanik und Strukturberechnung

Sekr. C 8-3, Geb. M

Str. des 17. Juni 135

D-10623 Berlin

Tel.: +49 (0) 30/314-21490

E-Mail: melika.mohammadkhah@tu-berlin.de 


\section{Table of Contents}

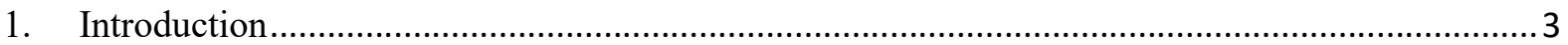

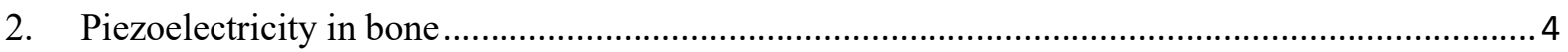

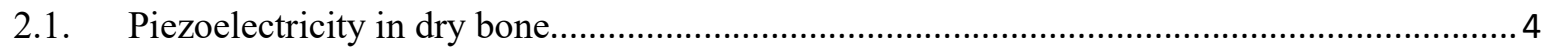

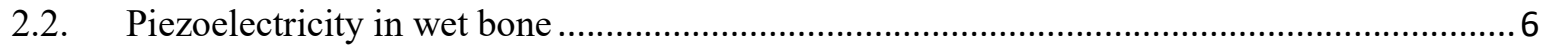

2.3. The importance of piezoelectricity in bone ......................................................................

3. In silico studies of the role of piezoelectricity on bone behavior................................................. 9

3.1. Computer models of bone electromechanical behavior (strain generated potentials).................9

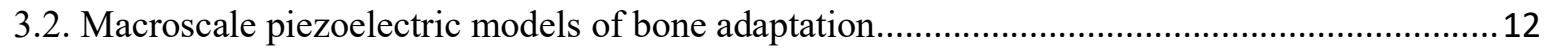

3.2.1. Multiscale/multiphysics piezoelectric models of bone adaptation......................................15

4. The clinical relevance of computational studies of bone piezoelectricity ...................................17

5. Limitations and future work in bone piezoelectric modeling ...................................................19

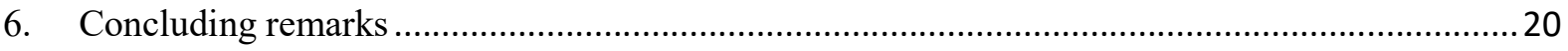

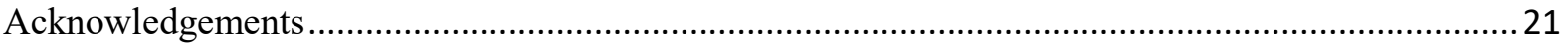

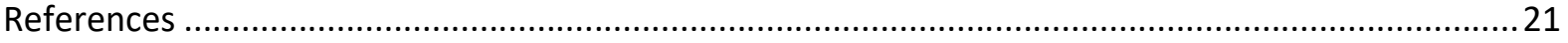

\section{Nomenclature}

\begin{tabular}{ll}
$V$ & Stress-generated voltage \\
$\Delta p$ & Pressure gradient \\
$\mathrm{L}$ & Sample thickness \\
$\mathrm{F}$ & Load applied to the sample \\
$\boldsymbol{P}$ & Electric polarization \\
$\boldsymbol{\sigma}$ & Stress \\
$\boldsymbol{\varepsilon}$ & Strain \\
$\boldsymbol{D}$ & Electric displacement \\
$\boldsymbol{\beta}$ & Dielectric permittivity tensor \\
$\boldsymbol{E}$ & Electric field \\
$\boldsymbol{\epsilon}$ & Piezoelectric stress tensor \\
$\boldsymbol{d}$ & Piezoelectric strain tensor \\
$\boldsymbol{u}$ & Displacement field \\
$\dot{u}$ & Rate of displacement normal to the bone surface \\
$\dot{U}$ & Velocity of the bone resorption process \\
$\boldsymbol{\gamma}$ & Flexoelectric tensor relating polarization and strain gradient \\
$\rho$ & Apparent density \\
$\chi \boldsymbol{u}$ & Dielectric susceptibility \\
$\mu$ and $\lambda$ & Lame's coefficients of the material \\
$\eta$ & Solution viscosity \\
$\sigma_{s}$ & Solution conductivity \\
$\mathrm{t}$ & Time \\
\hline
\end{tabular}




\begin{abstract}
Bone is a hierarchical, multiphasic and anisotropic structure which in addition posses piezoelectric properties. The generation of piezoelectricity in bone is a complex process which has been shown to play a key role both in bone adaptation and regeneration. In order to understand the complex biological, mechanical and electrical interactions that take place during these processes, several computer models have been developed and used to test hypothesis on potential mechanisms behind experimental observations. This paper aims to review the available literature on computer modeling of bone piezoelectricity and its application to bone adaptation and healing. We first provide a brief overview of the fundamentals of piezoelectricity and bone piezoelectric effects. We then review how these properties have been used in computational models of bone adaptation and electromechanical behaviour of bone. In addition, in the last section, we summarize current limitations and potential directions for future work.
\end{abstract}

\title{
Keywords
}

Bone piezoelectricity, Computer model, Bone adaptation and regeneration, Matrix piezoelectricity, Streaming potential, Strain Generated Potentials (SGP)

\section{Introduction}

In piezoelectric materials, deformation results in asymmetric shift of ions inducing a change in electric polarization and electricity is then generated. The conversion of physical deformation to electrical signals and vice versa is the key concept (see Figure 1). Microphones, speakers, fuel injection, hydrophones and actuator and sensor devices for active structures are some examples of industrial application of piezoelectricity [1-3].

Piezoelectricity also occurs naturally within the human body; bone, muscles and tendons present piezoelectric properties [4-7]. In bone, this behaviour has been attributed to semi-conductor characteristics [8,9], and to classic piezoelectric effects [5]. In addition, stress-generated electrical phenomena have been shown to direct the activity of bone cells and also to be responsible for the orientation or aggregation pattern of macromolecules in the extracellular matrix [8]. Moreover, piezoelectricity has been shown to play a role on bone adaptation and repair [10,11], and piezoelectric materials have been shown to enhance bone regeneration $[12,13]$. 


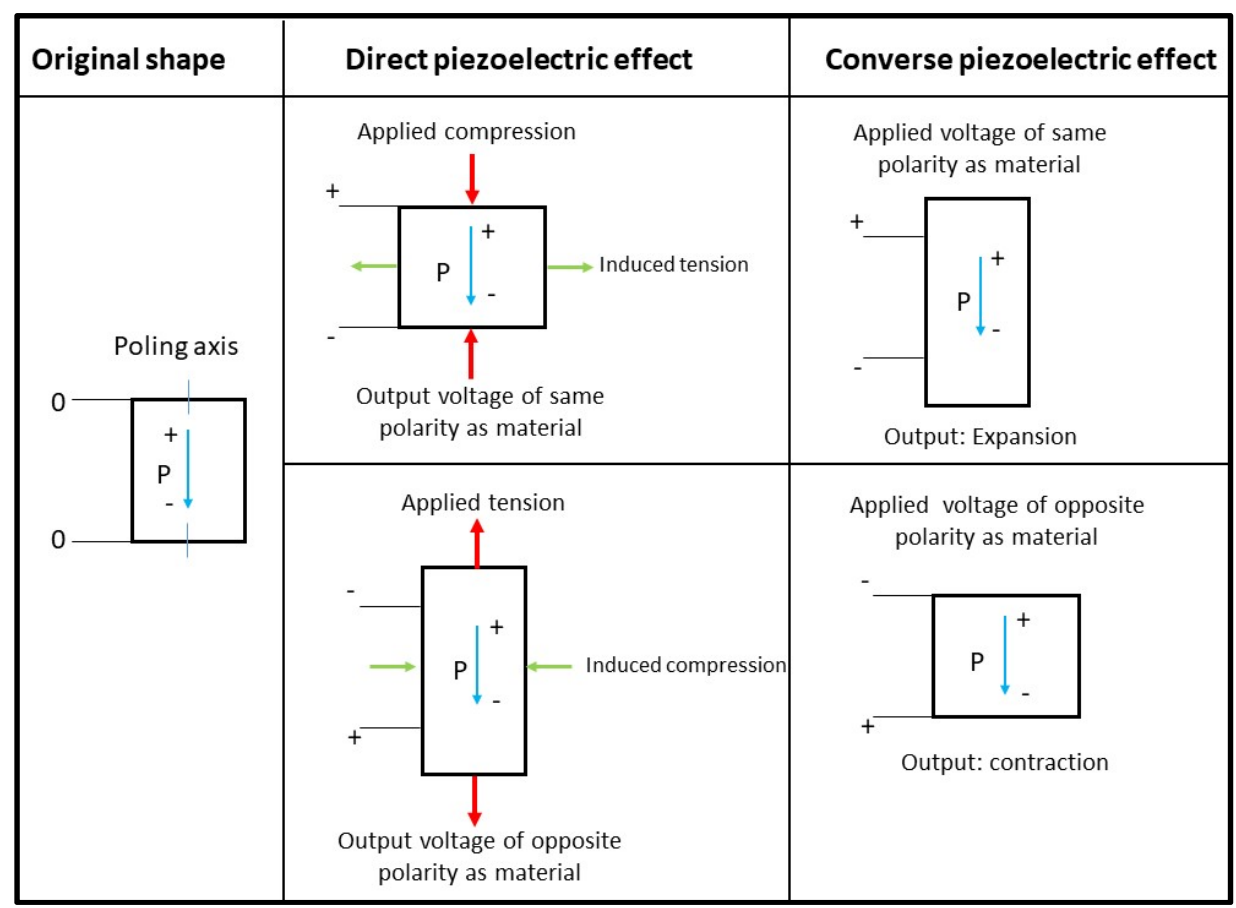

Figure 1. Schematic of direct and converse piezoelectric effect.

Although there has been a rapid increase in the number of publications on bone piezoelectric properties and the use of piezoelectric materials for bone regeneration and bone tissue engineering over the last few years $[12,14]$, the complexity behind piezoelectric effects in bone makes the design of piezoelectric materials very challenging. This complexity has promoted the developement of computer models to investigate the mechanisms behind experimental observations. Earlier computer models were mostly focused on modeling the piezoelectric properties of bone itself [15-17]. In the last decades, several multiscale/multiphysics models have also been developed to investigate coupled mechanisms; such as the influence of mechanically generated electrical signals on bone formation and resorption $[10,11$, 18-21]. This review aims to provide an overview of existing in silico studies focused on modeling piezoelectric effecs in bone and the knowledge they have provided. Lastly, an overview of current limitations and potential directions for future work are presented. We start the review with a brief overview on bone piezoelectric behaviour.

\section{Piezoelectricity in bone}

The exact mechanisms for the piezoelectric properties of bone are still not fully understood. Different piezoelectric responses have been measured for dry [5, 16, 22] and wet [23-25] bone which have been attributed to different processes taking place within the bone matrix.

\subsection{Piezoelectricity in dry bone}

The direct and converse piezoelectric properties of bone were first reported in 1954 by Yasuda for dry bone [22]. They attributed the piezoelectric behavior of bone to the application of shear to collagen 
fibers (matrix piezoelectricity). Quite recently, Minary-Jolandan and $\mathrm{Yu}$ [26] found that isolated type I collagen fibrils have unipolar axial polarizations and behave mainly as shear piezoelectric materials with a shear piezoelectric constant of $\mathrm{d}_{15} \approx 1 \mathrm{pC} \mathrm{N^{-1 }}$. This relatively dominant shear piezoelectric effect was the result of the quasihexagonal symmetry of the collagen fibril structure at the nanoscale [26]. Piezo-response force microscopy has also shown unidirectional polarization along the collagen fibril axis (direction 3), and negligible radial (direction 2) or vertical (direction 1) piezo-response [27].

Collagen (organic component of bone) is the major contributor to piezoelectric properties, but the calcium hydroxyapatite should not simply be observed as a passive component [28]. There are at least two reasons for the conductive role of calcium hydroxyapatite in matrix piezoelectricity: 1) Hydroxyapatite crystals show high elastic moduli, which ensures that loads applied on bone are transmitted across large scales while allowing the collagen fibers to mechanically respond locally. In case of smaller elastic moduli, collagen fibers probably bear the greatest strain of all the molecules within the solid matrix to generate the deformation needed for a piezoelectric effect. 2) Access of water to collagen is restricted by the hydroxyapatite, allowing the piezoelectric mechanisms to occur in dry bone even in the wet state: collagen in decalcified bone was shown to shrink upon heating, and permittivity of decalcified bone is higher than that of calcified bone due to higher adsorption of water [29].

Fukada and Yasuda [5] found that the amount of electric potential generated in bone depends on the direction of pressure applied with respect to the bone axis. They showed that when the pressure was applied at an angle of $45-50^{\circ}$ to the bone axis, a higher piezoelectric constant was observed. Fukada and Yasuda [7] demonstrated the existence of unique electrical axis in dry bone, however, further investigation showed that the direction of piezoelectric axis is both age-dependent and positiondependent, and the electromechanial moduli vary with position in bone [30, 31].

Matrix piezoelectricity is likely generated due to the molecular asymmetry of collagen, and it was defined as the primary mechanism for Strain-Generated Potentials (SGP) in dry bone. Time-dependent stress-generated voltage (calculated in the $i$ direction) originating from classic piezoelectricity theory for matrix piezoelectricity was proposed by Petrov [32] with the following equation:

$V=\left(\frac{d_{i i} \cdot L}{\beta_{i i}}\right) F \cdot \exp \left(-\frac{4 \pi \sigma_{s} t}{\beta_{i i}}\right)$

, where $d_{i i}$ is the component of piezoelectric stress tensor $(\boldsymbol{d})$; L, sample thickness; F, load applied to the sample (in the $i$ direction); $\sigma_{s}$, solution conductivity; $\beta_{i i}$, the component of dielectric permittivity tensor, and $t$ is the time. The charges generated by matrix piezoelectricity undergo quick relaxation.

\footnotetext{
${ }^{1} \mathrm{~d}_{15}$ is the induced polarization in direction 1 (perpendicular to direction 3 in which the material is polarized) per unit shear stress applied about direction 2 (direction 2 perpendicular to direction 3) or induced shear strain about direction 2 per unit electric field applied in direction 1.
} 
Relaxation time constants of 0.5-50 $\mu$ s were reported by classic dielectric measurements [23]. If matrix piezoelectricity was to dominate in bone, changes in conductivity and viscosity should not have changed the SGP amplitude. However, Pienkowski and Pollack [23] showed that viscosity and conductivity certainly influence the SGP amplitude. These observations led to diminish the importance of matrix piezoelectricity as a compelling mechanism for SGP, and drawn the researchers' attention to an alternative mechanism observed in wet bone.

\subsection{Piezoelectricity in wet bone}

Wet bone either exhibits lower piezoelectric effect compared to dry bone or the piezoelectric signal becomes more difficult to measure. It has been speculated that the incorporation of bound water molecules in a wet bone increases the conductivity of the moisture-filled matrix and the asymmetry of the collagen molecules and consequently reduces piezoelectric properties [23, 33]. Further research showed that streaming potentials, fluid and ions driven by mechanical loading, may also have a role in determining bone piezoelectric properties [34], and according to experimental findings, "streaming potential" was proposed as an alternative mechanism to matrix piezoelectricity and the primary drive for SGP in wet bone $[23,35]$. Streaming potential arises from the flow of a liquid across charged surfaces i.e. from the micropores filled with charged fluid. The fluids would be forced by a mechanical deformation through the canaliculi and accordingly a flow of ions is generated against the oppositely charged walls, resulting in a potential difference between two points along the stream [35]. To understand the streaming potential as an electro-kinetic phenomenon, the interface between a solid having a net surface charge density and a flowing ionic fluid must be understood. This interface presents different types of interactions (adsorption of ions, electrical and thermal effects) between an ionic liquid and a charged solid surface, which causes a spatially non-uniform distribution of charges near the interface known as double layer. Ions of opposite polarity are bound to the solid, which form a thin stationary layer resulting in an electrical potential varying from the solid surface to the bulk of the liquid. When a change in pressure causes the fluid to move relative to the solid fluid, there is a boundary called the slip plane that separates the thin stationary layer of fluid from the moving fluid. The zeta potential is defined as the electrical potential at the slip plane relative to the potential in the bulk of the fluid, which characterizes the electro-kinetic phenomenon in bone [15, 23].

To investigate the effects of fluid properties and structural variations of bone on the electromechanical properties of wet bone, Pollack et al. [36] suggested two important factors affecting fluid-related electromechanical properties. The authors reported that one factor is the geometry of the interconnecting porous matrix through which the fluid moves, which controls the direction, amplitude, and the time dependence of the fluid velocity. The second factor is the detailed structure of the double layer, which controls the electro-kinetic properties through the value of the zeta potential. At present, the typical method of studying the double layer structure is performed by changing the fluid ions type, concentration, and viscosity and observing alterations in the SGP. Pienkowski and Pollack [23] used a 
four point bending test on fluid-saturated bovine tibia to measure SGP and relaxation time as a function of $\mathrm{NaCl}$ concentration and viscosity, and found that the increase of the $\mathrm{NaCl}$ concentration of the soaking solution (the conductivity ranged from $0.01-10 \mathrm{~S} / \mathrm{m}$ ) caused decrease in the SGP amplitude, and SGP polarity above a certain concentration reversed. Over three orders of magnitude variation in solution conductivity, the relaxation time of the SGP was unaffected. They also showed that the SGP decreased with increasing solution viscosity while the relaxation time increased linearly. These findings are consistent with those of Gross and Williams [37]. SGP polarity reversed when the viscosity exceeds 20 folds that of water. However, the sign inversion of the SGP (at high $\mathrm{NaCl}$ concentrations) did not change with solution viscosities over the range of 1- 80 times of water viscosity. The amplitude of SGP measured in this study agreed to the SGP amplitudes measured by others [38-40]. The relaxation time for SGP in wet bone were reported in the range of 0.1-3 s [37, 41, 42], which is significantly larger than those expected for matrix piezoelectricity. The longer relaxation time is due to the viscosity of fluid. These findings of Pienkowski and Pollack [23] for SGP as a function of $\mathrm{NaCl}$ concentration and viscosity are, in part, explained by the following relationship:

$V=\frac{\xi \beta_{i i} \Delta p}{\sigma_{s} \eta}$

, where $V$ is the stress-generated voltage (in the $i$ direction); $\xi$ is the zeta potential; $\beta_{i i}$ is the component of dielectric permittivity tensor $(\boldsymbol{\beta}) ; \Delta p$ is the pressure gradient across a sample; $\sigma_{s}$ is solution conductivity, and $\eta$ is the solution viscosity. This scalar equation shows that the increase in solution viscosity and conductivity caused decrease in streaming potential. The polarity change of SGP is determined by the polarity change in zeta potential, and the higher concentrations of $\mathrm{NaCl}$ described by surface adsorption of positive ions (likely $\mathrm{Na}^{+}$) caused a shift towards a positive zeta potential. Equation (1) could not explain the amplitude or polarity of SGP observed in fluid-saturated bone, therefore Petrov [32] attributed the SGP in wet bone to a mechanism which generates a potential being dependent on both stress and stress gradient as also suggested by Williams and Breger [17]. However, these modifications could also not explain the viscosity effects and the relationship between the amplitude of SGP and properties of fluid in bone observed in Pienkowski and Pollack [23]. Perhaps one reason is that the $\mathrm{NaCl}$ concentration of the soaking solution may affect piezoelectric tensors.

Over the past decades, a large number of in vitro evidence demonstrates that fluid flow induces a variety of responses including piezoelectricity supporting bone adaptation [43-45]. However, in vivo studies emphasizing the role of interstitial fluid flow (IFF) to facilitate skeletal adaptation to mechanical loading is limited. In vivo, bone strain gradients produce measurable electro-kinetic potentials across the tissue [46]. Evidence showed that during mechanical loading stress-generated potentials recorded from the surface of bone are produced by streaming potentials generated by fluid flow through spaces in the bone matrix [37, 47], and transcortical streaming potential magnitudes are locally correlated to strain and strain gradient magnitudes $[8,37,47]$. In vivo at the peak load of $88 \mathrm{~N}$, transcortical streaming potential 
under axial loading was observed to be averagely 41.6 and $37.6 \mathrm{mV} / \mathrm{N}$, and under bending loading to be -120 and $156 \mathrm{mV} / \mathrm{N}$ in bone concave and convex sites respectively [46]. It has also been shown in vivo that intramedullary pressure (IMP) causes transcortical streaming potential, and significantly enhanced fluid movement in bone [42, 48-50]. Qin et al. [42] found out that at the peak IMP of 8.6 \pm 3.4 $\mathrm{kPa}$, the peak amplitude of the measured streaming potential was $0.39 \pm 0.14$ and $0.36 \pm 0.12 \mathrm{mV}$ at the convex and concave sites respectively.

In fluid-saturated bone, the piezoelectric component of the SGP may be visible when (1) the streaming potential component (zeta potential) is small or zero, (2) the applied stress does not produce a net flow of fluid between the potential measuring electrodes, (3) the fluid viscosity is very high [25]. According to streaming potential theory, assuming that a nonzero zeta potential exists at the bone-fluid interface, an SGP will be observed only if there exists a net flow of fluid between the SGP measuring electrodes. Iannacone et al. [25] observed no macroscopic SGPs from fluid-saturated human bone samples subjected to uniform compression because the uniform compression produced no net macroscopic flow of fluid. However, they reported that fluid flow did occur on a microscopic scale because the microelectrode recorded the potentials resulted from localized fluid flows in individual osteons.

Although none of the findings contradicts the suggestion that matrix piezoelectricity is the origin of SGPs in dry bone, these findings highly support the streaming potential mechanism and made it generally accepted for physiological conditions of bone. However, removing the collagen in a bone sample showed a decrease in the $\xi$-potential measurement [24]. In addition, the inversion of the streaming potential sign only happened where the collagen content is present [37]. As schematically illustrated in Figure 2, collagen's ability to affect bone's $\xi$-potential is a necessary prerequisite for streaming potential mechanism to play a role [28]. Furthermore, there must be an intrinsic system for osteocytes to differentiate the different types of bone stresses: axial compression vs. bending vs. shear within the fluid shear framework [28]. Microscopic assessment of bone shows that the architecture of collagen are uniquely suited to resist these stresses, and collagen due to its structured orientation and anisotropic piezoelectric property is an appealing candidate to provide the bone with the means for selective response of varying stresses [28, 51]. Nevertheless, as reviewed by Riddle and Donahue [52], in spite of the relevance of matrix piezoelectricity, investigations have mostly been conducted to understand the role of streaming potentials rather than matrix piezoelectricity for bone modelling and remodeling purposes [53]. However, now it is believed that both matrix piezoelectricity and streaming potential contribute to the electromechanical properties of bone. 


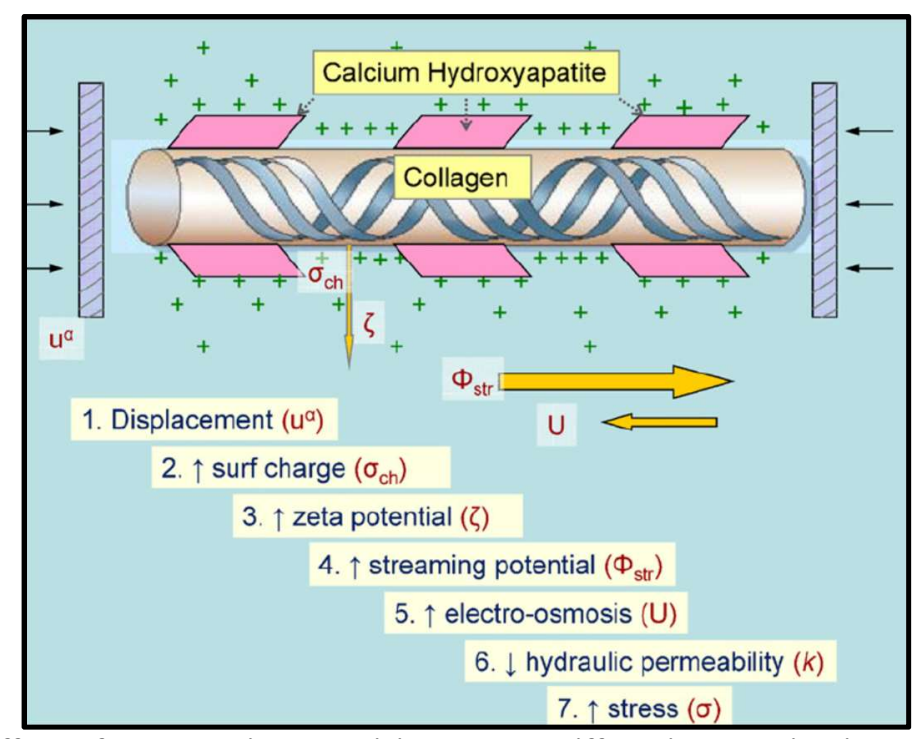

Figure 2. Theoretical effects of collagen piezoelectricity on bone stiffness in open-circuit conditions. Displacement of bone generates surface charges which increases zeta potential and streaming potential and indirectly contribute to greater stress and consequently greater bone stiffness (adapted from Ahn and Grodzinsky [28]).

\subsection{The importance of piezoelectricity in bone}

Bone adaptation: According to Wolff's law, developed by the German anatomist and surgeon Julius Wolff(1836-1902), bone adapts its internal shape and external conformation in response to the mechanical loads under which it is exposed to. This law is supported by the relation between bone density and physical activity [28]. Electrical measurements in bone [5] raised the idea that bone adaptation could be explained by "matrix piezoelectricity". In the 1960s, matrix piezoelectricity was introduced as a potential mechanism by which osteocytes could detect areas of higher stress. Therefore, traditionally, Wolff's Law was explained by piezoelectric properties of bone [28]. This theory states that applied stress generates local potential gradients along the collagen fibers and then provides a local stimulus for bone-generating cells $[8,9,54]$.

Bone cell activity: Discovery of piezoelectricity and transmembrane potentials has led to the development of technologies using electrical stimulation for cell and tissue growth. External electrical stimulation has been applied on transmembrane potentials to improve cellular growth and differentiation [12]. Methods used for osteogenic electrical stimulation range from applying electromagnetic waves using Helmholtz [55] and solenoid coils [56] [56] to capacitively coupled stimulation [57]. Capacitively coupled electrical stimulation has shown to significantly increase the proliferation [58] and matrix mineralization of osteoblast-like cells [57]. However, the mechanisms through which electrical stimulation changes proliferation and differentiation and causes cellular migration are not fully understood. It is hypothesized that the electric field affects proliferation and differentiation either directly by intracellular components such as ions, growth factors and receptors, or indirectly by conformational change of extracellular ions and proteins $[59,60]$. 
Bone regeneration: Electrical properties of bone are also relevant as an external electrical stimulation of bone to assist its healing and repair $[8,61,62]$. Axial electric signals have been used to regenerate limbs of salamander [63], and to stimulate the regrowth of portions of amputated limbs in rats [64], which do not usually regenerate [65]. Piezoelectric scaffolds used for bone regeneration have also shown promoted osteogenesis [66, 67], and improved cellular activity and desirable ontogenetic differentiation [68].

\section{In silico studies of the role of piezoelectricity on bone behavior}

\subsection{Computer models of bone electromechanical behavior (strain generated potentials)}

In the 1960s, the mechanical strains in compact bone were observed to generate electrical potential differences along the bone lateral and longitudinal axes [69]. However, different pattern and sign of generated voltage was observed in dry and wet bone [40, 53], suggesting that different electromechanical mechanism (matrix piezoelectricity and streaming potential) are involved in piezoelectric effects of dry and wet bone.

The first computer models of bone piezoelectricity mostly considered the characterization of SGP using linear piezoelectric theory. From a classic point of view of piezoelectric theory, end to end rotation of mineral samples in cantilever bending mode reverses the sign of the voltage, but does not change the sign of the generated potential for bone [17]. Williams and Breger [17] showed that the classic theory correctly describes both bone and piezoelectric crystals behavior to hydrostatic pressure. This theory also well predicts the crystals piezoelectric response in bending loading, but fails for bone in bending. Therefore, they suggested two modifications to the classic theory of piezoelectricity for bending loading of bone; 1) addition of a nonlinear relation between stress and polarization, and 2) addition of a term to relate the stress gradient and stress to polarization. They showed that the former (addition of $\sigma^{2}$ to the classic theory of piezoelectricity instead of $\sigma$ ) did not agree well with the experimental results. However, the addition of the stress gradient term, previously suggested by Fukada [70], yielded to better agree with their experiments. They concluded that the standard theory of piezoelectricity is sufficient to predict bone behavior in uniaxial compression, whereas the extended theory is required for bending [17]. The addition of a term relating strain gradient to polarization $\left(P_{i}\right)$ as stated above was also suggested by Kogan [71] as follows:

$$
P_{i}=\epsilon_{i j k} \varepsilon_{j k}+\gamma_{k l i j} \frac{\partial \varepsilon_{k l}}{\partial x_{j}}+\chi_{i j} E_{j}
$$


where $\epsilon_{i j k}$ is the piezoelectric strain tensor, $\varepsilon_{j k}$ is the strain tensor, $\gamma_{k l i}$ is the flexoelectric tensor relating polarization and strain gradient, $\frac{\partial \varepsilon_{k l}}{\partial x_{j}}$ is the spatial strain gradient, $\chi_{i j}$ is the dielectric susceptibility and $E_{j}$ is electric field.

In general, computational description of piezoelectric matrix is not compatible with values obtained from experiments for two main reasons; first as bone is polycrystalline in collagen, its directionality cannot be represented by a tensor for a single orientation of collagen; second the signs of any tensor is dependent only on its coordinates, however, the polarity of bone has been shown to be determined not by its spatial coordinates but by the sign of the stress [72]. Therefore, the best case is that the SGP tensor may be capable of characterizing magnitudes, but not the sign of those magnitudes. However, reports of only magnitudes for matrix of piezoelectric constants also differed significantly between theory and experiments [70, 73]. Korostoff [72] developed a model that satisfactorily accounts for all major experimental observations. They proposed that the reason for the change in the sign of SGP matrix resides in the microstructure of lamellar bone. Their model consists of single crystal collagen interacting with the structure of lamellar bone, which results in an unstable antiparallel piezoelectric polarization configuration in bone, and decouples the sign of the piezoelectric tensor from the bone coordinates. The SGP polarity in bending or tension/compression is determined by the stress gradient, and the polarity sign is determined by the sign reversion of zeta potential. The macroscopic SGP magnitude of bone in bending comes from the SGP third rank tensor, while this magnitude in tension or compression is in the range of zero up to the magnitude predicted by SGP tensor depending on the non-uniformity of the applied stress or the degree of structural irregularity in the specimen. Their model showed the large scatter in magnitude of polarity in samples in compression as well as the smaller magnitude of SGP in tension compared to compression [72]. The zero components of piezoelectric strain tensor presented by Fukada [70] were basically non-zero values proposed by others [73]. Following this observation and spatial-dependence of piezoelectric moduli in bone proposed by others [30, 31], Johnson et al. [16] proposed that perhaps there is a y-dependence in piezoelectric moduli of bone. They attempted to predict the voltage developed between opposed points on the compression and tension surfaces of a rectangular beam of dry bone subjected to cantilever bending where the $\mathrm{z}$ and $\mathrm{y}$ directions were the axial and vertical directions respectively. Therefore, they further modified the classic equation considering the spatial variation of the piezoelectric description of dry bone by calculating the electric field component $(\mathrm{E})$ in the $\mathrm{y}$-direction that can be integrated to yield the desired potential difference between the upper and lower surfaces of the specimen. The qualitative predictions of their model was confirmed by their experiments. However, the quantitative comparison showed agreement for ceramic material but not a straightforward agreement for dry bone. Their model could also not explain the effect of soaking solution properties on SGP They suggested that the apparently inconsistent piezoelectric 
behavior of bone in bending is a consequence of spatial variations in the local values of the piezoelectric moduli [16].

Bone has been shown to be a ferroelectric material (spontaneously polarized), and possesses a domain structure that their dipoles are prone to reorientation resulting from the applied strain [74-78]. Fukada and Takashita [79] in an experimental-theoretical study proposed that deformation of bone causes reorientation (in particular rotation) of dipoles in collagen associated with fibril bonds, and this reorientation then produces a net dipole moment resulting in an external potential. Following the observation of the stress-induced reorientation of dipoles in bone, Mahmud et al. [15] developed a model to characterize the strain-generated potential (SGP) of bone and its relationship to the reorientation of spontaneous dipoles of bone where mechanical deformation is applied. Their model relates the SGP signals to the reorientation of bone which has spontaneous dipoles whose arrangement can be changed by application of an electric field or mechanical stress. In their model, a sample is subjected to fixed amplitude step loading, which caused dipole rotation. Due to high loading rate, the dipoles reached maximum displacement, leading to a net bound charge of opposite polarity on the parallel sides of the specimen. Viscoelastic properties of bone then caused the charges to decay and return to their unstressed position. When the load was released the dipoles rotated in the opposite direction causing the reverse charge on the sides of the sample. This charge also decayed to zero due to stress relaxation. They stated that if the load rate is low, dipole rotation will not reach maximum displacement and therefore the generated potential will have a lower magnitude. They also reported that bone structure was responsible for the shape and magnitude of the generated potential [15].

\subsection{Macroscale piezoelectric models of bone adaptation}

For several decades, a number of theories have been proposed for bone adaptation to mechanical stresses. These theories are mostly focused on the effect of mechanical stimuli on bone formation and resorption. These theories explain the bone formation and resorption response based on strain energy $[11,80]$, deformation [81], stress [82], mechanical damage [83, 84], or a combination of them. In these studies, the nature of the received signals is assumed to be purely mechanical, and the mechanical stimuli acting on cells (pressure, shear stress, etc.) is mainly calculated from the poroelasticity theory [85]. However, the effect of combined mechanical and electrical loads has also been studied in the context of bone remodeling [21, 86-88].

To the best of the authors' knowledge, one of the primary efforts to incorporate piezoelectricity in bone modelling was a physical description of bone remodeling using simple piezoelectric linear theory presented by Gjelsvik [10]. In their model, the bone was assumed to be mechanically and electrically homogeneous and anisotropic. Bone adaptation was only considered at the macroscopic level. They applied the classic piezoelectric formulation to determine the electrical polarization $\left(P_{x}\right.$ is the $x$ 
component of polarization vector $\boldsymbol{P} ; x$ is the direction normal to bone surface) on the bone tissue due to stress caused by external loads. Since bone is fully enveloped in the periosteum, they assumed that a surface generated potential while loads are applied close to periosteum governs bone adaptation. They described the mechanism of bone remodeling as follows:

$$
\begin{array}{ll}
\dot{u}=a P_{x}-\dot{U} & \text { if } P_{x} \geq 0 \\
\dot{u}=b P_{x}-\dot{U} & \text { if } P_{x}<0
\end{array}
$$

where $\dot{u}$ is the rate of displacement normal to the surface: where it is greater than zero bone deposition occurs. $\dot{U}$ is the velocity of the resorption process, while $a$ and $b$ are constants. If the normal polarization vector (positive) is associated to deposition then $a$ is positive and $-a<b<a$. $\dot{u}$ greater than zero corresponds to bone deposition and $\dot{u}$ less than zero to resorption. Gjelsvik [10]'s model is based on several principles: (1) the piezoelectric polarization vector associated with bone surface is the stimulus for the surface remodeling, (2) the material direction of the new bone tends to align itself with the principal stress direction [54] or the new bone direction may simply follow the old bone direction independently of the stress system, (3) the new bone surface is deposited to remain stress free if it is unloaded.

Guzelsu and Demiray [89] presented a piezoelectric model to analyze a cantilever beam exposed to vertical load to identify the locations of maximum stress in compression and tension. Bassett et al. [9] proposed that on the convex surface tensile stress causes bone resorption, whereas on the concave surface bone formation is generated by compressive stress. However, Frost [90] explained that this is only suitable for periosteal surface not the endosteal. He then proposed the flexural neutralization theory, which states that bone response in the surface depends on the relative surface curvature. Decreased surface convexity cause bone formation and increased surface convexity causes bone resorption. However, this theory does not tell how the cells detect the surface curvature. Judex et al. [91] proposed an alternative theory which correlates the circumferential gradients of longitudinal strain and the sites of periosteal bone formation. Another theory based on the fluid flow along a pressure gradient from more compressed regions to more tensile was also proposed [92, 93]. Carpenter and Carter [94] assumed that pressure on periosteal surface obstruct bone formation and induce bone resorption, but tensile strains perpendicular to this surface cause bone deposition. All these models fail to predict endosteal remodeling. One possible theory that could explain why osteoclasts/osteoblasts have a tendency to work in some bone surfaces, could be the different electric change on each surface [11].

Garzón-Alvarado et al. [95] proposed a model of bone remodeling using mechanical and electrical stimuli, where the mechanical stimulus was descried by Nackenhorst [96] which depends on tissue density and the work performed by mechanical stress. The electrical stimulus depends on density, 
frequency and the work performed by the electric field. They showed that electrical stimulation generally result in a greater deposition of mass. Furthermore, the frequency of applied electric field affect the mass distribution; lower frequency causes more mass.

There are many theories mostly focusing on either bone modelling or remodeling. Currently there are few models representing both bone remodeling and modelling using piezoelectricity in bone [97]. Fernandez et al. [11] began to use a unified theory to justify both phenomena at both endosteal and periosteal surfaces. Their work also shows the relevant role of matrix piezoelectricity in bone modelling and remodeling under physiological loading conditions, and it holds importance particularly because the idea of incorporation of matrix piezoelectricity on bone adaptation slightly dimmed when other mechanisms, such as fluid-generated shear stress [86, 98] and streaming potential [36] were hypothesized. In their model bone was assumed to be isotropic elastic solid where the Elastic modulus is a function of the apparent density $\left(E(\rho)=M \cdot \rho^{c}\right)$, where $M=3790, c=3$, and $v=0.3$ given by Weinans et al. [99] characterizing the bone behavior. They introduced piezoelectricity in the model by extension of classical piezo-mechanical function, which guarantees that the electric field increases with the density of the bone.

They defined the stress tensor $(\boldsymbol{\sigma})$ and the electric displacement $(\boldsymbol{D})$ as follows:

$$
\begin{aligned}
& \boldsymbol{\sigma}=2 \mu(\rho) \boldsymbol{\varepsilon}(\boldsymbol{u})+\lambda(\rho) \operatorname{Div}(\boldsymbol{u}) I-\left(\frac{\rho}{\rho^{*}}\right)^{c} \boldsymbol{\epsilon}^{*} \boldsymbol{E}(\psi) \\
& \boldsymbol{D}=\boldsymbol{D}_{\boldsymbol{\varepsilon}}+\boldsymbol{D}_{\boldsymbol{E}}=\left(\frac{\rho}{\rho^{*}}\right)^{c} \boldsymbol{\epsilon} \boldsymbol{\varepsilon}(\boldsymbol{u})+\left(\frac{\rho}{\rho^{*}}\right)^{c} \boldsymbol{\beta} \boldsymbol{E}(\psi)
\end{aligned}
$$

Where $\boldsymbol{u}$ is the displacement field, $\boldsymbol{\varepsilon}$ is the strain tensor, $\boldsymbol{\epsilon}^{*}$ is the transpose of the piezoelectric stress tensor $(\boldsymbol{\epsilon}), \boldsymbol{E}(\psi)$ denotes the electric field, $\boldsymbol{\beta}$ is the dielectric permittivity tensor, $\rho^{*}$ is the reference value of $1.0 \mathrm{~g} / \mathrm{cm}^{3}, I$ and Div denote the identity and divergence operators respectively. $\mu(\rho)$ and $\lambda(\rho)$ are Lame's coefficients of the material depending on the apparent density, which were calculated using the values of Poisson's ratio and Young's modulus ${ }^{2}$. They also

assumed as others [21] that bone behaves like a crystal with hexagonal symmetry meaning that permittivity tensor $(\boldsymbol{\beta})$ is a diagonal matrix with two constants and piezoelectric stress tensor $(\boldsymbol{\epsilon})$ is defined by four values as shown in Table 1 .

$$
\boldsymbol{\epsilon}=\left(\begin{array}{cccccc}
0 & 0 & 0 & e_{14} & e_{15} & 0 \\
0 & 0 & 0 & e_{15} & -e_{14} & 0 \\
e_{31} & e_{31} & e_{33} & 0 & 0 & 0
\end{array}\right) \text { and } \boldsymbol{\beta}=\left(\begin{array}{ccc}
\beta_{11} & 0 & 0 \\
0 & \beta_{11} & 0 \\
0 & 0 & \beta_{33}
\end{array}\right)
$$

\footnotetext{
${ }^{2}$ For isotropic linear elastic material: $\mu=\frac{E}{2(1+v)}$ and $\lambda=\frac{E v}{(1+v)(1-2 v)}$
} 
Table 1 - Experimentally measured values of electromechanical properties used in the constitutive law of the bone piezoelectric behavior

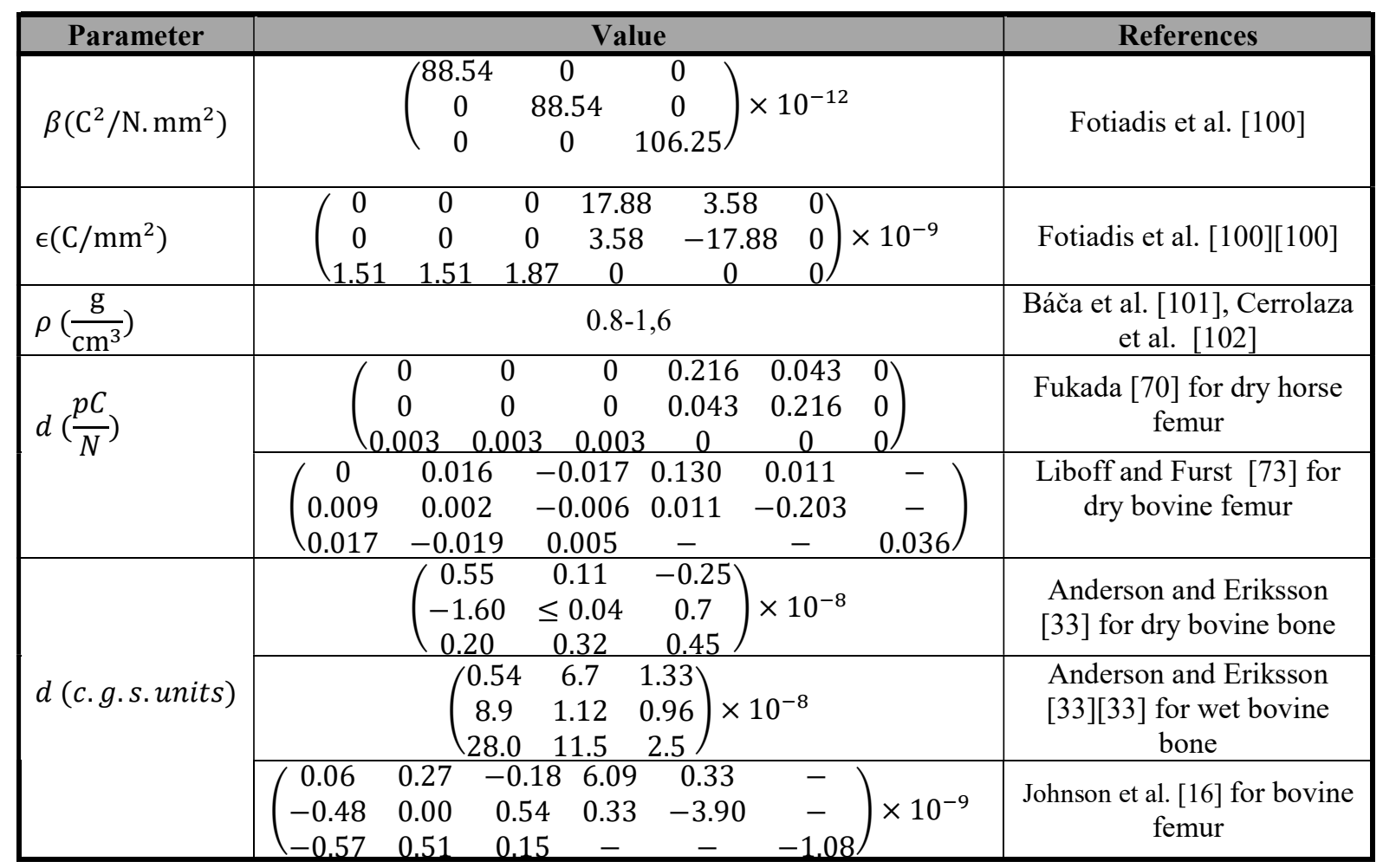

They concluded that negative charges cause bone resorption and positive charges leads to bone formation, which has also been proposed by other authors [21]; despite strong discrepancies in the piezoelectric strain tensor [33, 70,73], Fernandez et al. [11] showed that bone matrix piezoelectricity can explain how bone is selectively deposited or removed at different endosteal and periosteal surfaces by analysis of a diaphysis of a long bone with a malaligned fracture. They showed that bone in this case tends to be straighter, so on concave surfaces bone formation occurs.

More recently, Cerrolaza et al. [102] developed a model to study the piezoelectricity and its effects in bone remodeling using the Boundary Element Method (BEM) and a density function [11] to ensure the field increases. They assumed that the strain tensor and polarization vectors are a function of both stress and electric field for an elastic-piezoelectric body. They successfully showed the bone response to negative potentials, causing cell migration and bone deposition, and a bone resorption in positive potentials sites. They also showed that electrically loaded bone surfaces improved the bone deposition.

\subsubsection{Multiscale/multiphysics piezoelectric models of bone adaptation}

It is well known that osteocytes produce a signal as a response to mechanical loading, and they are thought to drive the bone remodeling response. Several authors have suggested that fluid shear effects [103], pericellular matrix deformation [104], interstitial fluid flow, ionic transport, and microcracks $[105,106]$, and chemo-electrical signals [18] trigger the remodelling process. Several multiphysics 
computer models have been developed to investigate the bone remodeling response [106-110]. Piezoelectricity in bone is also a multiscale phenomenon, where both matrix piezoelectricity and streaming potentials play an important role in determining the piezoelectric effects. Predoi-Racila and Crolet [111] presented a multiscale model of human cortical bone which considers piezoelectricity, elasticity and porous medium. Their model consisted of collagen of type 1, Hap crystals and "bony fluid containing cells". The collagen was considered as a piezoelectric medium (matrix piezoelectricity) and dielectric properties were used to model the presence of ions in the bony fluid. They proposed a behavior law considering the possibility for a medium to change its properties according to its degree of mineralization, so that when the mineralization becomes important in volume, the collagen fiber is locally embedded in Hap and cannot react to pressure variations. Therefore, Hap crystals surrounding the collagen establishes a sheath, which decreases or limits the piezoelectric effect progressively [111].

Following the idea from Ahn and Grodzinsky [28] that matrix piezoelectricity could cause a negatively charged environment for the interstitial fluid flow, Lemaire et al. [19] combined a description of electrokinetics in bone tissue $[18,110]$ with the description of piezobiomaterials [112] to derive a fully coupled electro-chemo-mechanical theoretical model of bone tissue. They proposed a multiscale theoretical investigation of bone electricity integrating the solid matrix electro-mechanics (matrix piezoelectricity), streaming potential and double layer effect developing in the bone porous network and electrochemical effect (interstitial fluid flow) inherent to osmotic pressure, and the solid-fluid interfacial phenomena. The solid phase was considered as a dielectric material where the polarization depends on both the strain and strain gradient, and the electrical behavior was assumed to obey Maxwell-Gauss equation. The fluid phase consisted of modeling the double layer and streaming potential, the fluid movement and the ionic transport. The double layer potential in the fluid phase followed the Poisson-Boltzmann equation and the Nernst-Planck convection-diffusionelectromigration equations were used which govern the ionic transport. Two different electric surface charges were introduced for the solid-fluid phase; surface charge density seen from the fluid or the solid [19]. Although due to the scaling laws, both the double layer and the matrix piezoelectric effects disappear through the homogenization process (their consequences are not macroscopically visible at the tissue level), their consequences at the microscopic scale can still exist. They concluded that a classical poroelasticity model combined with the usual Darcy law adequately describes the bone behaviour whereas, at the organ scale, in vivo electric measurement in living bone has to be attributed to streaming potential effects, but pure microscopic electrical effect may also exhibit indirect consequences such as the double layer potential in the diffusion tensor or pore surface charge density [19].

Bone piezoelectric properties have also been shown to be important in the context of bone regeneration $[13,113]$. Several experimental studies have investigated the potential of piezoelectric materials to promote bone repair [13]; however very limited work has been performed on multiscale modelling of 
bone piezoelectricity in the context of bone regeneration. To the best of authors' knowledge, there is only a 2D theoretical and numerical multiscale study of a bio-system (hybrid scaffold) composed of an artificial piezoelectric material perforated by holes which are interacting with living cells of bone [112]. Their criteria for assessment of bone cells in the piezoelectric matrix reflected in the ability of bone to induce (1) an increased adherence of osteoblasts on the piezoelectric material surface, and (2) an increased capacity for osteoblasts to produce larger amount of bone matrix. The piezoelectric scaffold was modelled using the classic piezoelectric equations. The cells were assumed to be composed of plasma membrane and the cytoskeletal network, therefore, the cell's behaviour was modelled using a linear isotropic matrix embedded with oriented fibres (microtubulae), which were modeled by a single additional constitutive parameter for strength of reinforcement. The micro-macro numerical simulation was performed using the homogenization method. The values of elasticity and dielectric tensors components of the living cells were obtained from Charras et al. [114], and were several orders of magnitude smaller than those of piezoelectric materials; hence at first no mechanical or electrical interference happened between the matrix and the living cells. However, under the stresses induced by the matrix on the boundary of the holes a rapid increase of the number of cells was predicted; which in turn changed the dielectric parameters in the living cells [112]. In this study, the authors investigated the mechano-electrical transduction on the interface between piezoelectric matrix and the cells, and showed that the electric field (in the same order of magnitude as the cell membrane potential field) generated by the matrix causes significant effects on the cells with both rectangular and circular cell shape of the same volume fraction [112]. Their proposed model, which predicted the growth of bone tissue, could control the osteoblast cells' activity as observed in vitro [57].

\section{The clinical relevance of computational studies of bone piezoelectricity}

Implantation of piezoelectric materials in vivo has shown promising results in bone and cartilage regeneration $[115,116]$, repairing nerve injuries [59, 117], breast cancer detection [118] and wound healing [119], which can be attributed to charge generation as a result of physiological stress and body movement on the piezoelectric material [12].

Biomedical piezoelectric applications surpassed only mimicking biological piezoelectric phenomena, and it is now very important in the medical industry as well [120]. Piezoelectric materials can be used in monitoring human vital signals such as pressure changes, heartbeat or breathing [121, 122]. An application for piezoelectric pressure sensing is synthetic skin where piezoelectric force transducers provide a solution to locate and quantify contact forces [123]. Chen-Glasser et al. [120] fully reviewed the applications of piezoelectric materials in surgery, microdosing and energy harvesting.

Shirazi Beheshtiha and Nackenhorst [124] developed a 3D FE piezoelectric model of bone remodeling surrounding the teeth implant. They employed the density dependent equation of piezoelectricity [95], 
and the thin bone-implant interface was described by the Drucker-Prager plasticity model. At the implant-support interface, the micromotions are reported to determine the long term success of implant. Therefore, they limited the osseointegration process by micromotion threshold. They showed that the micromotions decreased considerably, which is ideal. This model can be used for a dental implant to optimize new developed techniques for activating implants with piezo-electric coatings.

Recently, a computational model was developed to analyze the matrix piezoelectric behavior of the lumbar vertebral body in the remodeling process [125]. They particularly focused on the algorithms for the distribution of the density in bone and the simulation of the strain energy density for each point of the geometry. In addition, the model considers the bone to be piezoelectric and transversely isotropic. This 3D model contains the implementation of an algorithm which includes both the elastic and electric variables in a single equation using BEM. In their proposed piezoelectric model, both compact and spongy bone were considered. Spongy bone was defined as a homogeneous and isotropic material where the elastic modulus depends on bone density while the Poisson's ratio is constant. The compact bone was modelled as an anisotropic material where the constitutive tensor matrix is aligned with the distribution of the osteons in the compact bone. Bone adaptation was modelled by the electromechanical reactions which change the apparent density (internal bone remodeling process). This piezoelectric model of bone remodeling of the vertebra could predict the density distribution (bone formation or resorption) in agreement with tomographic data. They proposed that the numerical model could be used to understand the effect of electric stimulation on osteoporosis. These new findings can contribute to the development of new therapies or implants to help decrease bone loss and fracture risk [125].

In summary, the computer models that account for bone piezoelectric effects, their main features and conclusions are shown in Table 2.

Table 2- A brief review of the available computer models simulating bone piezoelectricity

\begin{tabular}{|c|c|c|c|c|}
\hline Authors & Application & $\begin{array}{l}\text { Theory * important } \\
\text { model features } \\
\text { *All models used classic } \\
\text { piezoelectric theory. } \\
\end{array}$ & $\begin{array}{l}\text { Mechanical } \\
\text { loading }\end{array}$ & Main Conclusion \\
\hline $\begin{array}{l}\text { Williams } \\
\text { and Breger } \\
\quad[17]\end{array}$ & $\begin{array}{l}\text { characterizati } \\
\text { on of SGP }\end{array}$ & $\begin{array}{l}\text { Addition of } \\
\text { the stress gradient }\end{array}$ & $\begin{array}{l}\text { Cantilever } \\
\text { bending/hydrost } \\
\text { atic pressure }\end{array}$ & $\begin{array}{l}\text { Classic piezoelectric theory } \\
\text { describes bone behavior to } \\
\text { hydrostatic pressure well, but } \\
\text { fails to describe the behavior } \\
\text { of bone in bending. }\end{array}$ \\
\hline \multirow{2}{*}{$\begin{array}{l}\text { Korostoff } \\
{[72]}\end{array}$} & \multirow{2}{*}{$\begin{array}{l}\text { characterizati } \\
\text { on of SGP }\end{array}$} & $\begin{array}{c}\text { Addition of } \\
\text { the stress gradient }\end{array}$ & \multirow{2}{*}{$\begin{array}{c}\text { Bending/compre } \\
\text { ssion }\end{array}$} & \multirow{2}{*}{$\begin{array}{l}\text { Smaller magnitude of SGP in } \\
\text { tension compared to } \\
\text { compression. }\end{array}$} \\
\hline & & $\begin{array}{c}\text { determination of SGP } \\
\text { polarity }\end{array}$ & & \\
\hline \multirow{2}{*}{$\begin{array}{l}\text { Johnson et } \\
\text { al. [16][16] }\end{array}$} & \multirow{2}{*}{$\begin{array}{c}\text { characterizati } \\
\text { on of SGP }\end{array}$} & $\begin{array}{c}\text { Addition of } \\
\text { the stress gradient }\end{array}$ & \multirow{2}{*}{$\begin{array}{l}\text { Cantilever } \\
\text { bending }\end{array}$} & \multirow{2}{*}{$\begin{array}{l}\text { Quantitative comparison of } \\
\text { computer model predictions } \\
\text { with experiments showed } \\
\text { good agreement for ceramic } \\
\text { material but not for dry bone. }\end{array}$} \\
\hline & & $\begin{array}{l}\text { Spatial variation of } \\
\text { piezoelectric moduli }\end{array}$ & & \\
\hline
\end{tabular}




\begin{tabular}{|c|c|c|c|c|}
\hline $\begin{array}{l}\text { Mahmud } \\
\text { et al. [15] }\end{array}$ & $\begin{array}{l}\text { characterizati } \\
\text { on of SGP }\end{array}$ & $\begin{array}{l}\text { Relating the SGP to the } \\
\text { reorientation of the bone } \\
\text { dipoles }\end{array}$ & $\begin{array}{l}\text { Step loading of } \\
\text { fixed amplitude } \\
\text { and duration }\end{array}$ & $\begin{array}{l}\text { Low load rates result in low } \\
\text { magnitude } \\
\text { potentials. }\end{array}$ \\
\hline $\begin{array}{l}\text { Gjelsvik } \\
{[10]}\end{array}$ & $\begin{array}{l}\text { Bone } \\
\text { adaptation } \\
\text { and } \\
\text { remodeling }\end{array}$ & $\begin{array}{l}\text { surface bone remodeling } \\
\text { is governed by } \\
\text { piezoelectricity }\end{array}$ & $\begin{array}{l}\text { Tension/compre } \\
\text { ssion }\end{array}$ & $\begin{array}{l}\text { (1) The piezoelectric } \\
\text { polarization vector associated } \\
\text { with the bone surface is the } \\
\text { stimulus for surface } \\
\text { remodeling. (2) the material } \\
\text { direction of the new bone } \\
\text { tends to align itself with the } \\
\text { principal stress direction or } \\
\text { the new bone direction may } \\
\text { simply follow the old bone } \\
\text { direction independently of the } \\
\text { stress system. (3) the new } \\
\text { bone surface is deposited to } \\
\text { remain stress free if it is } \\
\text { unloaded. }\end{array}$ \\
\hline \multirow{2}{*}{$\begin{array}{l}\text { Qu et al. } \\
\text { [87] }\end{array}$} & \multirow{2}{*}{$\begin{array}{l}\text { Bone } \\
\text { adaptation } \\
\text { and } \\
\text { remodeling }\end{array}$} & $\begin{array}{l}\text { Theoretical model of } \\
\text { bone modeling and } \\
\text { remodeling }\end{array}$ & \multirow[b]{2}{*}{ Compression } & \multirow{2}{*}{$\begin{array}{l}\text { Electromagnetic treatment } \\
\text { may cause bone hypertrophy, } \\
\text { although in some cases it can } \\
\text { be healed automatically. }\end{array}$} \\
\hline & & $\begin{array}{l}\text { Effect of extremely low- } \\
\text { frequency } \\
\text { electromagnetic field on } \\
\text { bone modeling }\end{array}$ & & \\
\hline \multirow{3}{*}{$\begin{array}{l}\text { Garzón- } \\
\text { Alvarado } \\
\text { et al. [95] }\end{array}$} & \multirow{3}{*}{$\begin{array}{l}\text { Bone } \\
\text { adaptation } \\
\text { and } \\
\text { remodeling }\end{array}$} & $\begin{array}{c}\text { Addition of spatial } \\
\text { density variation }\end{array}$ & \multirow{3}{*}{$\begin{array}{l}\text { Non-uniform } \\
\text { compression }\end{array}$} & \multirow{3}{*}{$\begin{array}{l}\text { Formation of cortical bone } \\
\text { occurred in the area remote } \\
\text { from the load and cancellous } \\
\text { bone in the areas close to load }\end{array}$} \\
\hline & & $\begin{array}{l}\text { Effect of frequency of } \\
\text { electric field on a } \\
\text { theoretical model of bone } \\
\text { remodeling }\end{array}$ & & \\
\hline & & $\begin{array}{c}\text { Finite element method } \\
(\text { FEM) }\end{array}$ & & \\
\hline \multirow[b]{2}{*}{$\begin{array}{l}\text { Fernandez } \\
\text { et al. [11] }\end{array}$} & \multirow[b]{2}{*}{$\begin{array}{l}\text { Bone } \\
\text { adaptation } \\
\text { and } \\
\text { remodeling }\end{array}$} & $\begin{array}{c}\text { Addition of spatial } \\
\text { density variation }\end{array}$ & \multirow[b]{2}{*}{ Compression } & \multirow{2}{*}{$\begin{array}{l}\text { Negative charges cause bone } \\
\text { resorption and positive } \\
\text { charges leads to bone } \\
\text { formation. } \\
\text { Bone matrix piezoelectricity } \\
\text { can explain how bone is } \\
\text { selectively deposited or } \\
\text { removed at different endosteal } \\
\text { and periosteal surfaces. }\end{array}$} \\
\hline & & FEM & & \\
\hline \multirow[b]{2}{*}{$\begin{array}{c}\text { Shirazi } \\
\text { Beheshtiha } \\
\text { and } \\
\text { Nackenhor } \\
\text { st [124] }\end{array}$} & \multirow[b]{2}{*}{$\begin{array}{l}\text { Bone } \\
\text { adaptation } \\
\text { and } \\
\text { remodeling }\end{array}$} & $\begin{array}{l}\text { Addition of spatial } \\
\text { density variation }\end{array}$ & \multirow[b]{2}{*}{ Compression } & \multirow{2}{*}{$\begin{array}{l}\text { This model showed decrease } \\
\text { of micromotions at implant- } \\
\text { support interface. This model } \\
\text { can be used for a dental } \\
\text { implant to optimize new } \\
\text { developed techniques for } \\
\text { activating implants with } \\
\text { piezo-electric coatings. }\end{array}$} \\
\hline & & FEM & & \\
\hline \multirow{3}{*}{$\begin{array}{l}\text { Cerrolaza } \\
\text { et al. [102] }\end{array}$} & \multirow{3}{*}{$\begin{array}{l}\text { Bone } \\
\text { adaptation } \\
\text { and } \\
\text { remodeling }\end{array}$} & $\begin{array}{l}\text { Addition of spatial } \\
\text { density variation }\end{array}$ & \multirow{3}{*}{$\begin{array}{l}\text { Compression at } \\
\text { trochanter and } \\
\text { femur head at an } \\
\text { angle }\end{array}$} & \multirow{3}{*}{$\begin{array}{l}\text { Bone deposition and } \\
\text { resorption response to } \\
\text { negative and positive } \\
\text { potentials, respectively }\end{array}$} \\
\hline & & $\begin{array}{l}\text { Consideration of dynamic } \\
\text { loading }\end{array}$ & & \\
\hline & & $\begin{array}{c}\text { Boundary element } \\
\text { method (BEM) }\end{array}$ & & \\
\hline \multirow{2}{*}{$\begin{array}{l}\text { Duarte et } \\
\text { al. [125] }\end{array}$} & \multirow{2}{*}{$\begin{array}{l}\text { Bone } \\
\text { adaptation } \\
\text { and } \\
\text { remodeling }\end{array}$} & $\begin{array}{l}\text { Addition of spatial } \\
\text { density variation }\end{array}$ & \multirow{2}{*}{$\begin{array}{l}\text { Physiological } \\
\text { flexion/extensio } \\
\mathrm{n}\end{array}$} & \multirow{2}{*}{$\begin{array}{l}\text { This piezoelectric model of } \\
\text { bone remodeling of the } \\
\text { vertebra could predict the } \\
\text { bone formation or resorption }\end{array}$} \\
\hline & & BEM & & \\
\hline
\end{tabular}




\begin{tabular}{|c|c|c|c|c|}
\hline & & & & $\begin{array}{l}\text { in agreement with } \\
\text { tomographic data }\end{array}$ \\
\hline \multirow{2}{*}{$\begin{array}{l}\text { Miara et } \\
\text { al. [112] }\end{array}$} & $\begin{array}{l}\text { Multiphysics/ } \\
\text { multiscale } \\
\text { model of } \\
\text { bone } \\
\text { remodeling }\end{array}$ & \multirow{2}{*}{$\begin{array}{l}\text { To model a matrix of } \\
\text { piezoelectric material } \\
\text { filled with living } \\
\text { osteoblast cells }\end{array}$} & \multirow{2}{*}{ Compression } & \multirow{2}{*}{$\begin{array}{l}\text { The electric field (in the same } \\
\text { order of magnitude as the cell } \\
\text { membrane potential field) } \\
\text { generated by the matrix causes } \\
\text { significant effects on the cells. }\end{array}$} \\
\hline & $\begin{array}{l}\text { biological } \\
\text { activity } \\
\text { within } \\
\text { piezoelectric } \\
\text { scaffold } \\
\end{array}$ & & & \\
\hline $\begin{array}{l}\text { Predoi- } \\
\text { Racila and } \\
\text { Crolet } \\
\text { [111] }\end{array}$ & $\begin{array}{l}\text { Multiphysics/ } \\
\text { multiscale } \\
\text { model of } \\
\text { bone } \\
\text { remodeling }\end{array}$ & $\begin{array}{c}\text { A complete } \\
\text { model of human cortical } \\
\text { bone called SiNuPrOs } \\
\text { accounting } \\
10 \text { physical properties, } 13 \\
\text { architectural organization } \\
\text { and } 5 \text { mineralization } \\
\text { parameters }\end{array}$ & $\begin{array}{l}\text { Fluid-generated } \\
\text { shear }\end{array}$ & $\begin{array}{l}\text { The proposed behavior law } \\
\text { considered the possibility for } \\
\text { a medium to change its } \\
\text { properties according to its } \\
\text { degree of mineralization, so } \\
\text { that when the mineralization } \\
\text { becomes important in volume, } \\
\text { the collagen fiber is locally } \\
\text { embedded in Hap and cannot } \\
\text { react to pressure variations. } \\
\text { Therefore, Hap crystals } \\
\text { surrounding the collagen } \\
\text { establishes a sheath, which } \\
\text { decreases or limits the } \\
\text { piezoelectric } \\
\text { progressively effect }\end{array}$ \\
\hline \multirow{4}{*}{$\begin{array}{l}\text { Lemaire's } \\
\text { group: } \\
{[18-20} \\
107,109]\end{array}$} & \multirow{4}{*}{$\begin{array}{l}\text { Multiphysics/ } \\
\text { multiscale } \\
\text { model of } \\
\text { bone } \\
\text { remodeling }\end{array}$} & $\begin{array}{l}\text { A theoretical modeling of } \\
\text { transport } \\
\text { phenomena, movement of } \\
\text { interstitial fluid, } \\
\text { piezoelectric properties } \\
\text { within cortical bone for } \\
\text { bone adaptation and } \\
\text { remodeling }\end{array}$ & \multirow{4}{*}{$\begin{array}{l}\text { Fluid-generated } \\
\text { shear }\end{array}$} & \multirow{4}{*}{$\begin{array}{l}\text { A classical poroelasticity } \\
\text { model combined with the } \\
\text { usual Darcy law adequately } \\
\text { describes the bone behaviour } \\
\text { whereas, at the organ scale, in } \\
\text { vivo electric measurement in } \\
\text { living bone has to be } \\
\text { attributed to streaming } \\
\text { potential effects, but pure } \\
\text { microscopic electrical effect } \\
\text { may also exhibit indiret } \\
\text { consequences such as the } \\
\text { double layer potential in the } \\
\text { diffusion tensor or pore } \\
\text { surface charge density }\end{array}$} \\
\hline & & Maxwell-Gauss equation & & \\
\hline & & $\begin{array}{c}\text { Nernst-Planck } \\
\text { convection-diffusion- } \\
\text { electromigration } \\
\text { equations }\end{array}$ & & \\
\hline & & $\begin{array}{l}\text { classic poroelasticity } \\
\text { model combined with the } \\
\text { usual Darcy law }\end{array}$ & & \\
\hline
\end{tabular}

\section{Limitations and future work in bone piezoelectric modeling}

Over the years, the complexity of the models have increased from early-developed models using classic equations of piezoelectricity to more sophisticated models taking into account the multiscale nature of the process, and employing both matrix piezoelectricity and streaming potentials as two mechanisms 
behind bone piezoelectricity at different scales. However, current piezoelectric models of bone lack some aspects, which require further work.

As previously shown, the piezoelectric tensors highly affect the bone adaptive response [11]. However, a model, which could appropriately predict the bone piezoelectric stress or strain tensor, is not available yet. Furthermore, since a large discrepancy has been reported in the literature on the piezoelectric strain tensors, the validation of the proposed piezoelectric models challenging. In addition, the common modeling assumption of bone to be electrically homogeneous is not supported by experimental evidence $[16,30,31]$. Therefore, further research is required to develop more realistic models to predict the piezoelectric properties of bone, which are also carefully validated with experimental data.

Another important challenge remains the development of computer models being able to explain the interactions between piezoelectric bone signals and the biological activity within the bone. Miara et al. [112] developed a detailed multiscale computer model to simulate bone cell growth and differentiation within a piezoelectric scaffold using the homogenization method. Although they were able to show the mechano-electrical transduction on the interface between piezoelectric matrix and the cells, many questions remain such as the influence of piezoelectric anisotropy on bone growth, effect of large deformations at the microscale and the proper homogenization for finite deformations [126], the influence of cell shape, and the consideration of sliding contact between cells and piezoelectric material with potential effect of delamination.

Piezoelectric signals have been shown to play a key role on bone regeneration and these effects have been positively used in the design of piezoelectric scaffolds to support bone healing $[13,113]$. In the last years, several computer models have been developed to investigate the bone regeneration process at the different scales and how it is influenced by mechanical signals $[127,128]$. However, up to now, there are no computer models of bone regeneration taking into account piezoelectric effects. Since piezoelectric materials hold promise as the next generation of tissue engineering scaffolds, computational models of piezoelectric scaffolds for bone healing and regeneration would have a remarkable potential to support the design of structures to promote bone regeneration. One of the main challenges behind these models will be to ensure that they can realistically predict the complexity of the regeneration process. To achieve this, they will have to be extensively validated against experimental data.

\section{Concluding remarks}

Over the last few years, there is a significant rise in the number of publications focusing on the piezoelectric materials for bone tissue engineering. Many studies have been performed on whether reproducing the biological electric fields can enhance growth and repair. Implantation of piezoelectric materials in vivo has prompted promising results in nerve injuries, bone formation and wound healing 
[14], which can be attributed to charge generation due to physiological stress on the piezoelectric material without the use of an external power source. Deformation of the piezoelectric scaffolds in vitro using mechanical or ultrasound stimuli has also caused enhanced adhesion, differentiation and faster cellular migration [13]. Even without deformation, piezoelectric scaffolds have shown positive protein adsorption, cellular attachment and proliferation, possibly due to permanent polarization and surface charges of piezoelectric materials or transient deformation caused by the contraction and protrusion of the attached cells $[13,113]$. In the current paper, the discovery of piezoelectric effects in bone and the different mechanisms describing this effect within bone were reviewed focused on computational models. We also showed that there are several remarkable experimental studies available in the literature to understand the effect of piezoelectricity on bone adaptation and healing and its applications in bone regeneration. In this review, we discuss about the available models to study the inherent piezoelectricity observed in bone, and those which employed piezoelectric effect to model bone adaptation. However, still the development of piezoelectric models to predict bone healing is missing, which is a remarkable potential for future direction of this field.

\section{Acknowledgements}

This study was partially supported by the German Research Foundation (Deutsche Forschungsgemeinshaft $\mathrm{CH} 1123 / 4-1$ and $\mathrm{CH} 1123 / 4-2$ to SC).

\section{References}

[1] V.Y. Topolov, C. R. Bowen, and P. Bisegna, "New aspect-ratio effect in three-component composites for piezoelectric sensor, hydrophone and energy-harvesting applications," Sensors and Actuators A: Physical, vol. 229, pp. 94-103, 2015.

[2] U. Gabbert, F. Duvigneau, and S. Ringwelski, "Noise control of vehicle drive systems," Facta Universitatis, Series: Mechanical Engineering, vol. 15, no. 2, pp. 183-200, 2017.

[3] G. Ciofani et al., "Applications of piezoelectricity in nanomedicine," Piezoelectric nanomaterials for biomedical applications, pp. 213-238, 2012.

[4] E. Fukada and H. Ueda, "Piezoelectric Effect in Muscle," Japanese Journal of Applied Physics, vol. 9, no. 7, pp. 844-845, 1970.

[5] E. Fukada and I. Yasuda, "On the piezoelectric effect of bone," Journal of the physical society of Japan, vol. 12, no. 10, pp. 1158-1162, 1957.

[6] E. Fukada and K. Hara, "Piezoelectric Effect in Blood Vessel Walls," Journal of the physical society of Japan, vol. 26, no. 3, pp. 777-780, 1969.

[7] E. Fukada and I. Yasuda, "Piezoelectric Effects in Collagen," Japanese Journal of Applied Physics, vol. 3, no. 2, pp. 117-121, http://dx.doi.org/10.1143/JJAP.3.117, 1964.

[8] C. A. L. Bassett and R. O. Becker, "Generation of electric potentials by bone in response to mechanical stress," Science, vol. 137, no. 3535, pp. 1063-1064, 1962. 
[9] C. A. L. Bassett, R. J. Pawluk, and R. O. Becker, "Effects of Electric Currents on Bone In Vivo," Nature, vol. 204, 652 EP -, http://dx.doi.org/10.1038/204652a0, 1964.

[10] A. Gjelsvik, "Bone remodeling and piezoelectricity. I," (eng), J Biomech, vol. 6, no. 1, pp. 69-77, 1973.

[11] J. R. Fernandez, J. M. Garcia-Aznar, and R. Martínez, "Piezoelectricity could predict sites of formation/resorption in bone remodelling and modelling," Journal of theoretical biology, vol. 292, pp. 86-92, 2012.

[12] A. H. Rajabi, M. Jaffe, and T. L. Arinzeh, "Piezoelectric materials for tissue regeneration: A review," Acta biomaterialia, vol. 24, pp. 12-23, 2015.

[13] B. Tandon, J. J. Blaker, and S. H. Cartmell, "Piezoelectric materials as stimulatory biomedical materials and scaffolds for bone repair," Acta biomaterialia, 2018.

[14] C. Ribeiro, V. Sencadas, D. M. Correia, and S. Lanceros-Méndez, "Piezoelectric polymers as biomaterials for tissue engineering applications," Colloids and Surfaces B: Biointerfaces, vol. 136, pp. 46-55, 2015.

[15] F. A. Mahmud, G. W. Hastings, and M. Martini, "Model to characterize strain generated potentials in bone," Medical engineering \& physics, vol. 10, no. 1, pp. 54-56, 1988.

[16] M. W. Johnson, W. S. Williams, and D. Gross, "Ceramic models for piezoelectricity in dry bone," J Biomech, vol. 13, no. 7, pp. 565-573, 1980.

[17] W. S. Williams and L. Breger, "Piezoelectricity in tendon and bone," J Biomech, vol. 8, no. 6, pp. 407-413, 1975.

[18] T. Lemaire, S. Naïli, and A. Rémond, "Study of the influence of fibrous pericellular matrix in the cortical interstitial fluid movement with hydroelectrochemical effects," Journal of biomechanical engineering, vol. 130, no. 1, p. 11001, 2008.

[19] T. Lemaire et al., "A Multiscale Theoretical Investigation of Electric Measurements in Living Bone," Bulletin of Mathematical Biology, vol. 73, no. 11, pp. 2649-2677, https://doi.org/10.1007/s11538-011-9641-9, 2011.

[20] T. Lemaire, E. Capiez-Lernout, J. Kaiser, S. Naili, and V. Sansalone, "What is the importance of multiphysical phenomena in bone remodelling signals expression? A multiscale perspective," Journal of the Mechanical Behavior of Biomedical Materials, vol. 4, no. 6, pp. 909-920, 2011.

[21] Q.-H. Qin and J.-Q. Ye, "Thermoelectroelastic solutions for internal bone remodeling under axial and transverse loads," International Journal of Solids and Structures, vol. 41, no. 9-10, pp. 24472460, 2004.

[22] I. Yasuda, "On the piezoelectric activity of bone," J Jpn Orthop Surg Soc, vol. 28, no. 3, p. 267, 1954.

[23] D. Pienkowski and S. R. Pollack, "The origin of stress-generated potentials in fluid-saturated bone," J. Orthop. Res., vol. 1, no. 1, pp. 30-41, 1983.

[24] M. Otter, S. Goheen, and W. S. Williams, "Streaming potentials in chemically modified bone," $J$. Orthop. Res., vol. 6, no. 3, pp. 346-359, 1988.

[25] W. Iannacone, E. Korostoff, and Pollack, SR, "Microelectrode study of stress-generated potentials obtained from uniform and nonuniform compression of human bone," J. Biomed. Mater. Res., vol. 13, no. 5, pp. 753-763, 1979. 
[26] M. Minary-Jolandan and M.-F. Yu, "Nanoscale characterization of isolated individual type I collagen fibrils: Polarization and piezoelectricity," Nanotechnology, vol. 20, no. 8, p. 85706, 2009.

[27] M. Minary-Jolandan and M.-F. Yu, "Uncovering nanoscale electromechanical heterogeneity in the subfibrillar structure of collagen fibrils responsible for the piezoelectricity of bone," Acs Nano, vol. 3, no. 7, pp. 1859-1863, 2009.

[28] A. C. Ahn and A. J. Grodzinsky, "Relevance of collagen piezoelectricity to "Wolff's Law": A critical review," Medical engineering \& physics, vol. 31, no. 7, pp. 733-741, 2009.

[29] E. Marzec, L. Kubisz, and F. Jaroszyk, "Dielectric studies of proton transport in air-dried fully calcified and decalcified bone," International journal of biological macromolecules, vol. 18, no. 1-2, pp. 27-31, 1996.

[30] H. Athenstaedt, "Permanent Longitudinal Electric Polarization and Pyroelectric Behaviour of Collagenous Structures and Nervous Tissue in Man and other Vertebrates," Nature, vol. 228, no. 5274, pp. 830-834, https://doi.org/10.1038/228830a0, 1970.

[31] H. Athenstaedt, "Permanent electric polarization and pyroelectric behaviour of the vertebrate skeleton. I. The axial skeleton of the vertebrates (excluding Mammalia)," (eng), Zeitschrift fur Zellforschung und mikroskopische Anatomie (Vienna, Austria : 1948), vol. 91, no. 1, pp. 135-152, 1968.

[32] N. Petrov, "On the electromechanical interaction in physiologically wet bone," Biomechanics, vol. 2, pp. 43-52, 1975.

[33] J. C. Anderson and C. Eriksson, "Piezoelectric properties of dry and wet bone," Nature, vol. 227, no. 5257, p. 491, 1970.

[34] La MacGinitie, G. D. Stanley, W. A. Bieber, and D. D. Wu, "Bone streaming potentials and currents depend on anatomical structure and loading orientation," Journal of Biomechanics, vol. 30, no. 11-12, pp. 1133-1139, 1997.

[35] G. W. Hastings and F. A. Mahmud, "Electrical effects in bone," Journal of biomedical engineering, vol. 10, no. 6, pp. 515-521, 1988.

[36] S. R. Pollack, N. Petrov, R. Salzstein, G. Brankov, and R. Blagoeva, "An anatomical model for streaming potentials in osteons," Journal of Biomechanics, vol. 17, no. 8, pp. 627-636, http://www.sciencedirect.com/science/article/pii/0021929084900940, 1984.

[37] D. Gross and W. S. Williams, "Streaming potential and the electromechanical response of physiologically-moist bone," J Biomech, vol. 15, no. 4, pp. 277-295, 1982.

[38] Pollack, SR, E. Korostoff, M. E. Sternberg, and J. Koh, "Stress-generated potentials in bone: Effects of collagen modifications," J. Biomed. Mater. Res., vol. 11, no. 5, pp. 677-700, 1977.

[39] W. Starkebaum, Pollack, SR, and E. Korostoff, "Midroelectrode studies of stress-generated potentials in four-point bending of bone," J. Biomed. Mater. Res., vol. 13, no. 5, pp. 729-751, 1979.

[40] G. V.B. Cochran, R. J. Pawluk, and C. A.L. Bassett, "24 Electromechanical Characteristics of Bone Under Physiologic Moisture Conditions," Clinical orthopaedics and related research, vol. 58, pp. 249-270, 1968.

[41] M. W. Otter, Y. X. Qin, C. T. Rubin, and K. J. McLeod, "Does bone perfusion/reperfusion initiate bone remodeling and the stress fracture syndrome?," Medical hypotheses, vol. 53, no. 5, pp. 363368, http://www.sciencedirect.com/science/article/pii/S0306987798907824, 1999. 
[42] Y.-X. Qin, W. Lin, and C. Rubin, "The pathway of bone fluid flow as defined by in vivo intramedullary pressure and streaming potential measurements," Annals of biomedical engineering, vol. 30, no. 5, pp. 693-702, 2002.

[43] L. You et al., "Osteocytes as mechanosensors in the inhibition of bone resorption due to mechanical loading," (eng), Bone, vol. 42, no. 1, pp. 172-179, https://www.ncbi.nlm.nih.gov/pubmed/17997378, 2008.

[44] S. D. Tan et al., "Osteocytes subjected to fluid flow inhibit osteoclast formation and bone resorption," Bone, vol. 41, no. 5, pp. 745-751, 2007.

[45] P. S. Vezeridis, C. M. Semeins, Q. Chen, and J. Klein-Nulend, "Osteocytes subjected to pulsating fluid flow regulate osteoblast proliferation and differentiation," Biochemical and Biophysical Research Communications, vol. 348, no. 3, pp. 1082-1088, 2006.

[46] B. R. Beck, Y. X. Qin, K. J. McLeod, and M. W. Otter, "On the relationship between streaming potential and strain in an in vivo bone preparation," Calcified tissue international, vol. 71, no. 4, pp. 334-343, 2002.

[47] M. W. Otter et al., "A comparative analysis of streaming potentials in vivo and in vitro," J. Orthop. Res., vol. 10, no. 5, pp. 710-719, 1992.

[48] R. Y. Kwon, D. R. Meays, W. J. Tang, and J. A. Frangos, "Microfluidic enhancement of intramedullary pressure increases interstitial fluid flow and inhibits bone loss in hindlimb suspended mice," Journal of Bone and Mineral Research, vol. 25, no. 8, pp. 1798-1807, 2010.

[49] A. Fahlgren et al., "Fluid pressure and flow as a cause of bone resorption," Acta orthopaedica, vol. 81, no. 4, pp. 508-516, 2010.

[50] C. Price, X. Zhou, W. Li, and L. Wang, "Real-time measurement of solute transport within the lacunar-canalicular system of mechanically loaded bone: direct evidence for load-induced fluid flow," Journal of Bone and Mineral Research, vol. 26, no. 2, pp. 277-285, 2011.

[51] T. G. Bromage et al., "Circularly polarized light standards for investigations of collagen fiber orientation in bone," The Anatomical Record Part B: The New Anatomist: An Official Publication of the American Association of Anatomists, vol. 274, no. 1, pp. 157-168, 2003.

[52] R. C. Riddle and H. J. Donahue, "From streaming-potentials to shear stress: 25 years of bone cell mechanotransduction," J. Orthop. Res., vol. 27, no. 2, pp. 143-149, 2009.

[53] M. Otter, J. Shoenung, and W. S. Williams, "Evidence for different sources of stress-generated potentials in wet and dry bone," J. Orthop. Res., vol. 3, no. 3, pp. 321-324, 1985.

[54] C. A. L. Bassett, "Biologic significance of piezoelectricity," Calcified tissue research, vol. 1, no. 1, pp. 252-272, 1967.

[55] C. H. Lohmann et al., "Pulsed electromagnetic field stimulation of MG63 osteoblast-like cells affects differentiation and local factor production," J. Orthop. Res., vol. 18, no. 4, pp. 637-646, 2000 .

[56] W. H.-S. Chang, L.-T. Chen, J.-S. Sun, and F.-H. Lin, "Effect of pulse-burst electromagnetic field stimulation on osteoblast cell activities," Bioelectromagnetics: Journal of the Bioelectromagnetics Society, The Society for Physical Regulation in Biology and Medicine, The European Bioelectromagnetics Association, vol. 25, no. 6, pp. 457-465, 2004. 
[57] H.-P. Wiesmann, M. Hartig, U. Stratmann, U. Meyer, and U. Joos, "Electrical stimulation influences mineral formation of osteoblast-like cells in vitro," Biochimica et Biophysica Acta (BBA)-Molecular Cell Research, vol. 1538, no. 1, pp. 28-37, 2001.

[58] H. Zhuang et al., "Electrical stimulation induces the level of TGF- $\beta 1$ mRNA in osteoblastic cells by a mechanism involving calcium/calmodulin pathway," Biochemical and Biophysical Research Communications, vol. 237, no. 2, pp. 225-229, 1997.

[59] N. Patel and M.-M. Poo, "Orientation of neurite growth by extracellular electric fields," Journal of Neuroscience, vol. 2, no. 4, pp. 483-496, 1982.

[60] C. E. Schmidt, V. R. Shastri, J. P. Vacanti, and R. Langer, "Stimulation of neurite outgrowth using an electrically conducting polymer," Proceedings of the National Academy of Sciences, vol. 94, no. 17, pp. 8948-8953, 1997.

[61] C. A. L. Bassett, A. A. Pilla, and R. J. Pawluk, "A non-operative salvage of surgically-resistant pseudarthroses and non-unions by pulsing electromagnetic fields. A preliminary report," Clinical orthopaedics and related research, no. 124, pp. 128-143, 1977.

[62] R. O. Becker, "The significance of bioelectric potentials," Bioelectrochemistry and Bioenergetics, vol. 1, no. 1-2, pp. 187-199, 1974.

[63] R. O. Becker, "Search for evidence of axial current flow in peripheral nerves of salamander," Science, vol. 134, no. 3472, pp. 101-102, 1961.

[64] R. O. Becker, "Stimulation of partial limb regeneration in rats," Nature, vol. 235, no. 5333, p. 109, 1972.

[65] R. O. Becker and J. A. Spadaro, "Electrical stimulation of partial limb regeneration in mammals," Bulletin of the New York Academy of Medicine, vol. 48, no. 4, p. 627, 1972.

[66] F. Jianqing, Y. Huipin, and Z. Xingdong, "Promotion of osteogenesis by a piezoelectric biological ceramic," Biomaterials, vol. 18, no. 23, pp. 1531-1534, 1997.

[67] A. Ehterami, M. Kazemi, B. Nazari, P. Saraeian, and M. Azami, "Fabrication and characterization of highly porous barium titanate based scaffold coated by Gel/HA nanocomposite with high piezoelectric coefficient for bone tissue engineering applications," Journal of the Mechanical Behavior of Biomedical Materials, vol. 79, pp. 195-202, http://www.sciencedirect.com/science/article/pii/S1751616117305878, 2018.

[68] X. Zhang et al., "Nanocomposite membranes enhance bone regeneration through restoring physiological electric microenvironment," Acs Nano, vol. 10, no. 8, pp. 7279-7286, 2016.

[69] Z. B. Friedenberg and C. T. Brighton, "Bioelectric potentials in bone," JBJS, vol. 48, no. 5, pp. 915-923, 1966.

[70] E. Fukada, "Mechanical deformation and electrical polarization in biological substances," Biorheology, vol. 5, no. 3, pp. 199-208, 1968.

[71] S. M. Kogan, "Piezoelectric effect during inhomogeneous deformation and acoustic scattering of carriers in crystals,” Soviet Physics-Solid State, vol. 5, no. 10, pp. 2069-2070, 1964.

[72] E. Korostoff, "A linear piezoelectric model for characterizing stress generated potentials in bone," J Biomech, vol. 12, no. 5, pp. 335-347, 1979.

[73] A. R. Liboff and M. Furst, "Pyroelectric effect in collagenous structures," Annals of the New York Academy of Sciences, vol. 238, no. 1, pp. 26-35, 1974. 
[74] M. A. El Messiery, G. W. Hastings, and S. Rakowski, "Ferro-electricity of dry cortical bone," Journal of biomedical engineering, vol. 1, no. 1, pp. 63-65, 1979.

[75] G. W. Hastings, M. A. ElMessiery, and S. Rakowski, "Mechano-electrical properties of bone," Biomaterials, vol. 2, no. 4, pp. 225-233, 1981.

[76] M. E. Steinberg, R. E. Wert, E. Korostoff, and J. Black, "Deformation potentials in whole bone," Journal of Surgical Research, vol. 14, no. 3, pp. 254-259, 1973.

[77] J. Cohen and S. Edelman, "Piezoelectric effect in oriented polyvinylchloride and polyvinylflouride," Journal of Applied Physics, vol. 42, no. 8, pp. 3072-3074, 1971.

[78] N. Guzelsu and W. R. Walsh, "Piezoelectric and electrokinetic effects in bone tissue-review," Electro-and Magnetobiology, vol. 12, no. 1, pp. 51-82, 1993.

[79] E. Fukada and S. Takashita, "Piezoelectric constant in oriented $\beta$-form polypeptides," Japanese Journal of Applied Physics, vol. 10, no. 6, p. 722, 1971.

[80] R. Huiskes et al., "Adaptive bone-remodeling theory applied to prosthetic-design analysis," Journal of Biomechanics, vol. 20, no. 11-12, pp. 1135-1150, 1987.

[81] V. A. Papathanasopoulou, D. Fotiadis, G. Foutsitzi, and C. V. Massalas, "A poroelastic bone model for internal remodeling," International Journal of Engineering Science, vol. 40, no. 5, pp. 511-530, 2002.

[82] H. Gong, L. Kong, R. Zhang, J. Fang, and M. Zhao, "A femur-implant model for the prediction of bone remodeling behavior induced by cementless stem," Journal of Bionic Engineering, vol. 10, no. 3, pp. 350-358, 2013.

[83] S. Ramtani, "Electro-mechanics of bone remodelling," International Journal of Engineering Science, vol. 46, no. 11, pp. 1173-1182, 2008.

[84] G. Martínez, J. M. G. Aznar, M. Doblaré, and M. Cerrolaza, "External bone remodeling through boundary elements and damage mechanics," Mathematics and Computers in Simulation, vol. 73, no. 1-4, pp. 183-199, 2006.

[85] M. A. Biot, "General theory of three-dimensional consolidation," Journal of Applied Physics, vol. 12 , no. 2 , pp. $155-164,1941$.

[86] S. C. Cowin, S. Weinbaum, and Y. Zeng, "A case for bone canaliculi as the anatomical site of strain generated potentials," Journal of Biomechanics, vol. 28, no. 11, pp. 1281-1297, 1995.

[87] C. Qu, Q.-H. Qin, and Y. Kang, "A hypothetical mechanism of bone remodeling and modeling under electromagnetic loads," Biomaterials, vol. 27, no. 21, pp. 4050-4057, 2006.

[88] C.-Y. Qu and S.-W. Yu, "The damage and healing of bone in the disuse state under mechanical and electro-magnetic loadings," Procedia Engineering, vol. 10, pp. 171-176, 2011.

[89] N. Guzelsu and H. Demiray, "Electromechanical properties and related models of bone tissues: A review," International Journal of Engineering Science, vol. 17, no. 7, pp. 813-851, 1979.

[90] H. M. Frost, The laws of bone structure: Springfield, Ill., Thomas, 1964.

[91] S. Judex, T. S. Gross, and R. F. Zernicke, "Strain gradients correlate with sites of exercise-induced bone-forming surfaces in the adult skeleton," Journal of Bone and Mineral Research, vol. 12, no. 10, pp. 1737-1745, 1997. 
[92] L. Y. Mi, M. Basu, S. P. Fritton, and S. C. Cowin, "Analysis of avian bone response to mechanical loading, Part Two: Development of a computational connected cellular network to study bone intercellular communication," Biomechanics and modeling in mechanobiology, vol. 4, no. 2-3, pp. 132-146, 2005.

[93] L. Y. Mi, S. P. Fritton, M. Basu, and S. C. Cowin, "Analysis of avian bone response to mechanical loading - Part One: distribution of bone fluid shear stress induced by bending and axial loading," Biomechanics and modeling in mechanobiology, vol. 4, no. 2-3, pp. 118-131, 2005.

[94] R. D. Carpenter and D. R. Carter, "The mechanobiological effects of periosteal surface loads," Biomechanics and modeling in mechanobiology, vol. 7, no. 3, pp. 227-242, 2008.

[95] D. A. Garzón-Alvarado, A. M. Ramírez-Martínez, and de Martínez, Carmen Alicia Cardozo, "Numerical test concerning bone mass apposition under electrical and mechanical stimulus," Theoretical Biology and Medical Modelling, vol. 9, no. 1, p. 14, 2012.

[96] U. Nackenhorst, "Numerical simulation of stress stimulated bone remodeling," Technische Mechanik, vol. 17, no. 1, pp. 31-40, 1997.

[97] Q.-H. Qin and Q.-S. Yang, Macro-micro theory on multi-field coupling behavior of heterogeneous materials: Springer, 2008.

[98] V.-H. Nguyen, T. Lemaire, and S. Naili, "Poroelastic behaviour of cortical bone under harmonic axial loading: A finite element study at the osteonal scale," Medical engineering \& physics, vol. 32, no. 4, pp. 384-390, 2010.

[99] H. Weinans, R. Huiskes, and H. J. Grootenboer, "The behavior of adaptive bone-remodeling simulation models," J Biomech, vol. 25, no. 12, pp. 1425-1441, 1992.

[100] D. Fotiadis, G. Foutsitzi, and C. V. Massalas, "Wave propagation modeling in human long bones," Acta mechanica, vol. 137, no. 1-2, pp. 65-81, 1999.

[101] V. Báča, D. Kachlík, Z. Horák, and J. Stingl, "The course of osteons in the compact bone of the human proximal femur with clinical and biomechanical significance," Surgical and Radiologic Anatomy, vol. 29, no. 3, pp. 201-207, 2007.

[102] M. Cerrolaza, V. Duarte, and D. Garzón-Alvarado, "Analysis of Bone Remodeling Under Piezoelectricity Effects Using Boundary Elements," Journal of Bionic Engineering, vol. 14, no. 4, pp. 659-671, 2017.

[103] I. Westbroek et al., "Differential stimulation of prostaglandin G/H synthase-2 in osteocytes and other osteogenic cells by pulsating fluid flow," Biochemical and Biophysical Research Communications, vol. 268, no. 2, pp. 414-419, 2000.

[104] Y. Han, S. C. Cowin, M. B. Schaffler, and S. Weinbaum, "Mechanotransduction and strain amplification in osteocyte cell processes," Proceedings of the National Academy of Sciences, vol. 101, no. 47, pp. 16689-16694, 2004.

[105] R. B. Martin, "Is all cortical bone remodeling initiated by microdamage?," Bone, vol. 30, no. 1, pp. 8-13, 2002.

[106] S. P. Fritton and S. Weinbaum, "Fluid and solute transport in bone: flow-induced mechanotransduction," Annual review of fluid mechanics, vol. 41, pp. 347-374, 2009.

[107] T. Lemaire, J. Kaiser, S. Naili, and V. Sansalone, "Three-scale multiphysics modeling of transport phenomena within cortical bone," Mathematical Problems in Engineering, vol. 2015, 2015. 
[108] V.-H. Nguyen, T. Lemaire, and S. Naili, "Influence of interstitial bone microcracks on straininduced fluid flow," Biomechanics and modeling in mechanobiology, vol. 10, no. 6, pp. 963-972, 2011.

[109] T. Lemaire and S. Naili, "Multiscale approach to understand the multiphysics phenomena in bone adaptation," in Multiscale Computer Modeling in Biomechanics and Biomedical Engineering: Springer, 2013, pp. 31-72.

[110] T. Lemaire, S. Naiili, and A. Rémond, "Multiscale analysis of the coupled effects governing the movement of interstitial fluid in cortical bone," Biomechanics and modeling in mechanobiology, vol. 5, no. 1, pp. 39-52, 2006.

[111] M. Predoi-Racila and J. M. Crolet, "Human cortical bone: the SiNuPrOs model: Part Idescription and elastic macroscopic results," Computer Methods in Biomechanics and Biomedical Engineering, vol. 11, no. 2, pp. 169-187, 2008.

[112] B. Miara, E. Rohan, M. Zidi, and B. Labat, "Piezomaterials for bone regeneration designhomogenization approach," Journal of the Mechanics and Physics of Solids, vol. 53, no. 11, pp. 2529-2556, 2005.

[113] G. Turnbull et al., "3D bioactive composite scaffolds for bone tissue engineering," Bioactive materials, 2017.

[114] G. T. Charras, P. P. Lehenkari, and M. A. Horton, "Atomic force microscopy can be used to mechanically stimulate osteoblasts and evaluate cellular strain distributions," Ultramicroscopy, vol. 86, no. 1-2, pp. 85-95, 2001.

[115] S. M. Damaraju et al., "Three-dimensional piezoelectric fibrous scaffolds selectively promote mesenchymal stem cell differentiation," Biomaterials, vol. 149, pp. 51-62, 2017.

[116] N. More and G. Kapusetti, "Piezoelectric material-a promising approach for bone and cartilage regeneration," Medical hypotheses, vol. 108, pp. 10-16, 2017.

[117] P. Aebischer et al., "Piezoelectric nerve guidance channels enhance peripheral nerve regeneration," ASAIO Journal, vol. 33, no. 3, pp. 457-458, 1987.

[118] K. Park, W. Chen, M. A. Chekmareva, D. J. Foran, and J. P. Desai, "Electromechanical Coupling Factor of Breast Tissue as a Biomarker for Breast Cancer," IEEE Transactions on Biomedical Engineering, vol. 65, no. 1, pp. 96-103, 2018.

[119] B. Reid and M. Zhao, "The electrical response to injury: molecular mechanisms and wound healing," Advances in wound care, vol. 3, no. 2, pp. 184-201, 2014.

[120] M. Chen-Glasser, P. Li, J. Ryu, and S. Hong, "Piezoelectric Materials for Medical Applications," in Piezoelectricity-Organic and Inorganic Materials and Applications: IntechOpen, 2018.

[121] S. Seneviratne et al., "A survey of wearable devices and challenges," IEEE Communications Surveys \& Tutorials, vol. 19, no. 4, pp. 2573-2620, 2017.

[122] J. Park, M. Kim, Y. Lee, H. S. Lee, and H. Ko, "Fingertip skin-inspired microstructured ferroelectric skins discriminate static/dynamic pressure and temperature stimuli," Science advances, vol. 1, no. 9, e1500661, 2015.

[123] J. Dargahi, "A piezoelectric tactile sensor with three sensing elements for robotic, endoscopic and prosthetic applications," Sensors and Actuators A: Physical, vol. 80, no. 1, pp. 23-30, 2000. 
[124] A. Shirazi Beheshtiha and U. Nackenhorst, "Computational simulation of piezo-electrically stimulated bone remodeling surrounding teeth implant," PAMM, vol. 15, no. 1, pp. 111-112, 2015.

[125] V. d. J. Duarte, K. Thoeni, D. Garzón-Alvarado, and M. Cerrolaza, "A Simplified Scheme for Piezoelectric Anisotropic Analysis in Human Vertebrae Using Integral Methods," Mathematical Problems in Engineering, vol. 2018, 2018.

[126] E. Rohan, "Sensitivity strategies in modelling heterogeneous media undergoing finite deformation," Mathematics and Computers in Simulation, vol. 61, no. 3-6, pp. 261-270, 2003.

[127] L. Podshivalov, A. Fischer, and P. Z. Bar-Yoseph, "On the Road to Personalized Medicine: Multiscale Computational Modeling of Bone Tissue," Archives of Computational Methods in Engineering, vol. 21, no. 4, pp. 399-479, https://doi.org/10.1007/s11831-014-9120-1, 2014.

[128] A. Carlier, L. Geris, J. Lammens, and H. van Oosterwyck, "Bringing computational models of bone regeneration to the clinic," Wiley Interdisciplinary Reviews: Systems Biology and Medicine, vol. 7, no. 4, pp. 183-194, 2015. 